\title{
Should Investors on Equity Markets Be Superstitious? (Example of 7 World Stock Indexes Components)
}

\author{
Krzysztof Borowski ${ }^{1}$ \\ ${ }^{1}$ Warsaw School of Economics, Warsaw, Poland \\ Correspondence: Krzysztof Borowski, Warsaw School of Economics, Warsaw 02-513, ul. Madalinskiego 6/8, \\ Poland. Tel: 48-510-275-217. E-mail: krzysztof.borowski@sgh.waw.pl
}

Received: October 9, 2018

Accepted: December 21, 2018

Online Published: December 27, 2018

doi:10.5539/ijef.v11n1p151

URL: https://doi.org/10.5539/ijef.v11n1p151

\begin{abstract}
The problem of efficiency of financial markets, especially the weekend effect has always fascinated scholars and practitioners due to its relationship with the financial market efficiency. The issue is significant from the point of view of assessing the portfolio management effectiveness and behavioral finance. This paper tests the hypothesis of the unfortunate dates effect upon 7 equity indexes components (CAC40, DAX, DJIA, FTSE30, FTSE MIBTEL, NIKKEI225 and SENSEX), i.e. 419 companies. For all these equities the following rates of return were analyzed: Close-close, Overnight, Open-open, Open-close. As unfortunate days, the sessions falling on the following dates were selected: $13^{\text {th }}$ and $4^{\text {th }}$ day of the month, Friday the $13^{\text {th }}$ and Tuesday the $13^{\text {th }}$. The research proved the presence of all kinds of the "unfortunate dates" effects on analyzed markets. The effects were registered for all analyzed rates of return. The most dominating "unfortunate dates effects" resulted to be Tuesday the $13^{\text {th }}$, proceeding the $4^{\text {th }}$ day of the month effect. This is the first analysis of the presence of the "unfortunate dates effect", in which other than Close-close returns were examined and fulfils the research gap.
\end{abstract}

Keywords: market efficiency, calendar anomalies, Friday the $13^{\text {th }}$, Tuesday the $13^{\text {th }}$, unfortunate dates effect

\section{Introduction}

Efficient market hypothesis (EMH), introduced by Fama (Fama, 1970) belongs to the most important paradigms of the traditional financial theories. According to this hypothesis, efficient market is defined as a market with a large numbers of rational individuals, maximizing their profit and actively competing with each other undertaking the attempt to predict future market values of specific securities, and where all relevant information is freely available to investors (Latif et al., 2011). The presence of calendar anomalies has been presented extensively for the last three decades in financial markets. The most common ones are the day-of-the-week effect, monthly effect, weekend effect, holiday effects, within-the-month effect, turn-of-the month effect (Agrawal, Tandon, 1994; Boudreaux, 1995; Smirlock \& Starks, 1986; Aggarval \& Rivoli, 1989; Barone, 1990; Kato et al., 1990; Gu, 2003; Schwert, 2002; Sutheebanjard \& Premchaiswadi, 2010).

Another issue related to the financial market efficiency is the behavior of investors during the days considered by them to be unlucky. In Western Europe, every $13^{\text {th }}$ day of the month, especially the $13^{\text {th }}$ day of the month when falling on a Friday is to be believed unlucky. In turn, in Spanish-speaking countries (e.g. Spain, Uruguay, Argentina, Chile, Peru, Venezuela and Colombia), it is assumed that the date of bringing bad luck is Tuesday the $13^{\text {th }}$, what is expressed in the following Spanish proverb: trece martes ni te cases, ni te embarques (Tuesday the $13^{\text {th }}$, don't get married and don't travel). On the other hand, in China, an unlucky date is every fourth day of the month. Many Chinese people believe the number 4 is to be unlucky whilst considering the number 8 is a lucky one (Agarwal et al., 2014). In some Chinese dialects, the number 8 is pronounced like the word "prosperity", while the number 4 similar to the word "death". Apparently the Chinese vary in their definition of which numbers are lucky. Shum et al. (2012) defined both 6 and 8 as lucky, while Hirshleifer et al. (2018) considered 6, 8 and 9 to be lucky.

Statistically important difference between daily average rates of return registered on the stock market considered by investors as an unlucky date and daily average rates of return calculated for the others days of the month can be called "the unfortunate dates effect". The number of papers dedicated to "the unfortunate dates effect" in scientific literature is rather low. 
The aim of this paper is to examine the prevalence of "the unfortunate dates effect" on the markets of 7 world equity index components. The paper is divided into five parts. The first four parts analyze of "the unfortunate dates effect" that apply to the returns calculated on the basis of the following prices: (1) last session close previous session close (close-close), (2) last session open - previous session close (overnight), (3) last session open - previous session open (open-open) and (4) last session close - last session open (open-close). All calculations will be carried out for the following two populations: (1) the $13^{\text {th }}$ day of the month rates of return vs rates of return for all other sessions, (2) Friday the $13^{\text {th }}$ rates of return vs rates of return for all other sessions, (3) Tuesday the $13^{\text {th }}$ rates of return vs rates of return for all other sessions and (4) the $4^{\text {th }}$ day of month rates of return vs rates of return for all other sessions. In the fifth part of the paper the one-session rates of return for Friday the $13^{\text {th }}$ session will be compared with the one-session rates of return for all other Fridays. In turn, in the second part of the fifth part of the paper the similar analysis for rates of return for Tuesday the $13^{\text {th }}$ and all other Tuesdays will be conducted. Previous researches focused on the calculation of rates of return only for the following scheme: Friday the $13^{\text {th }}$ close - others Fridays' close. The author is not aware of the papers analyzing the Friday the $13^{\text {th }}$ effect with the use of rates of return different to the close-close scheme. This article attempts to fill this gap, as well as expand research for Tuesday the $13^{\text {th }}$ and for the sessions falling on the $4^{\text {th }}$ day of the month.

\section{Literature Review}

Belief in the ill-fortune that supposedly accompanies the of $13^{\text {th }}$ as well as the date of Friday the $13^{\text {th }}$ is widespread across the Western world and has ancient and somewhat uncertain origins (Boyle et al., 2004). Both the number 13 and Friday are characterized by long and separate histories associated with "bad luck". It is believed that these two were combined in order to create an unfortunate date at the beginning of the $20^{\text {th }}$ Century (Chaundler, 1970). In the literature there are a lot of explanations for these two lines of superstitions: Christ was crucified on Friday, and the number of people seated at the table for the Last Supper was 13. Even in developed countries, people are prone to superstitions such as daily newspapers publishing horoscopes to guide their readers. Nowadays many buildings skip the thirteenth floor, streets lack the number $13^{\text {th }}$ and hospitals in many countries decline to label their operating theatres with that number (Hira et al., 1998; Reilly \& Stevenson, 2000; Boyle et al., 2004; USA, Today, 2007; Kramer \& Block, 2008). Of more interest is the fact that admittance to hospitals seems to cluster around unlucky days, as reported by Blacher (1983) and Scanon et al. (1993). Fudenberg and Levine (2006) state that superstitious beliefs can persist if the probability of being exposed as untrue is sufficiently low. If there is always any chance of a bad outcome when following superstition and some chance of a good outcome when not following superstition, any person might not realize that the belief is untrue, and, persists in the superstition (Agarval et al., 2014). Jiang et al. (2009) found that Asians exposed to lucky numbers, give higher estimates of winning a lottery and are more willing to participate in a lottery or a risky promotional game, and express greater willingness to make risky financial investments. Chong and Du (2009) estimated the value of superstition: a lucky (unlucky) number can bring good (bad) luck, and the value of superstitions can be economically significant. Psychology and anthropology researchers suggest that people rely on superstition as a way to cope with misfortune and uncertainty, and to rationalize a complex world (Vyse, 1997; Tsang, 2004; Lepori, 2009; Liu, 2013, Zhang et al., 2014, Robiyanto \& Puryandani, 2015, Robiyanto et al., 2015).

Scanlon et al. (1993) founded that the number of traffic accident in UK is higher on Friday the $13^{\text {th }}$, in spite of the smaller number on cars being on the roads. Kolb and Rodriguez (1987), in one of the first studies linking superstition with the stock market, proved that in the period of $1962-1985$, the average Friday $13^{\text {th }}$ rates of return of CRSP Index are significantly lower than the average rates of return for all other Fridays. Later papers of Dyl and Maberly (1988), Agrawal and Tandon (1994), Coutts (1999), Lucey (2000) and Lucey (2001) conceded the reverse pattern: average returns on Fridays the $13^{\text {th }}$ were higher than those on regular Fridays. Dyl and Maberly (1988) proved that in the analyzed time horizon of 1940-1987, in five out of the six analyzed periods, Friday the $13^{\text {th }}$ rates of return turned out to be positive and higher compared to other Fridays and the only period when the Friday the $13^{\text {th }}$ rates of return were in red compared to other Fridays rates of return, fell during the 1970s. The similar conclusion was reached in the research of Agrawal and Tandon (1994) as well as of Mills and Coutts (1995). Chamberlain et al. (1991) examining behavior of rates of return falling on Friday the $13^{\text {th }}$ during the period of 1930-1985 found no stronger evidence of lower mean returns for Fridays falling on the $13^{\text {th }}$.

Fortin et al. (2014) investigated the effect of superstition on the prices of single-family homes in Great Vancouver in Canada. In neighborhoods with relatively more Chinese residents and in repeated transaction, the sales of prices of houses with street address numbers ending in " 4 " were $2.2 \%$ lower, while those ending in " 8 " were $2.5 \%$ higher than other houses. According to Agarwal et al. (2014), on a per square meter basis, units with numbers ending in " 4 " were discounted by $1.1 \%$, units on floor with numbers ending in " 4 " were discounted by $0.5 \%$, while units with 
numbers ending in " 8 " commanded a $0.9 \%$ premium. There are also reports of a link between the superstition beliefs of certain time periods and the demographics of two nations: Japanese (Kaku, 1972; Kaku \& Matsumoto, 1975; Kaku, 1975) and Koreans (Kim, 1979). Ng et al. (2010) studying the auction prices between 1997 and 2009 proved that the prices of license numbers including the lucky number 8 were systematically higher while prices of license numbers with the unlucky number " 4 ", were lower. Besides the premium for " 8 " could also be interpreted as conspicuous spending to signal wealth or status (Feltovith et al., 2012).

Boyle et al. (2004), analyzing daily returns of the index NZSE40, the value-weighted capital index of the 40 largest securities by market capitalization on the New Zealand Stock Exchange in the period 01.01.1967-30.11.2001 proved that the average rates of return for the Fridays the $13^{\text {th }}$ were not statistically different form the rates of return for regular Fridays. The name of "the Friday the Thirteenth effect", introduced by Kolb and Rodriguez (Kolb \& Rodriguez, 1987) has been regularly used by different researchers (Chamberlain et al., 1991; Coutts, 1999; Patel 2009; Botha, 2013; Auer \& Rottmann, 2013). Coutts (1999) examining the Friday the $13^{\text {th }}$ effect in the UK with the use of FTSE index in the period of 59 years, proved that in most cases the rates of return registered for Friday the $13^{\text {th }}$ were positive and higher compared to other Fridays rates of return, but statistical significance was not observed. Patel (2009), analyzing the period of 58 years for NASDAQ and S\&P 500 index, discovered that in four out of the seven periods rates of return for Friday the $13^{\text {th }}$ were positive and higher than the rates of return calculated for other Fridays.

Brown et al. (2002) and Brown and Mitchell (2008) discovered that the daily opening and closing prices tend to cluster at the number "8" in Asian Pacific and Chinese Stock markets. Hirshleifer et al. (2018) found that the superstition affected the pricing of initial public offerings in China in the period of 1991-2005. On Shanghai and Shenzhen stock exchanges, listed companies are identified by a numerical code, which is the equivalent of the US ticker. Consistent with superstition, newly listed equities with lucky listing codes (that included at least one lucky digit and no unlucky digit) initially traded at a premium dissipated within three years. Botha (2013) analyzed the Friday the $13^{\text {th }}$ effect for samples from stock exchanges in Kenya, Morocco, Nigeria, South Africa and Tunisia. Auer and Rottmann (2013) investigating the presence of Friday the $13^{\text {th }}$ effect for seven emerging markets in Asia (India, Indonesia, Malaysia, Philippines, South Korea, Taiwan and Thailand) during the period of July 1996-August 2013, proved that the effect was registered on the Stock Exchange in Phillipines. They also found that the Friday the $13^{\text {th }}$ effect had a significant influence on the stock market volatility in Indonesia and the Philippines. Chung and Darrat (2014) examined the potential effect of superstitious beliefs on stock trading in four Asian-Pacific countries with deep Chinese cultural heritage (China, Hong Kong, Singapore, and Taiwan). The regression results from daily data over 2 January 1991 to 30 December 2011 suggest that unlucky days (particularly day 4 and Friday the 13th) generally exhibit higher stock returns. Kalayaan (2016) found out that the mean returns for Friday the $13^{\text {th }}$ were inferior than that of other Fridays or other days and that the Friday the $13^{\text {th }}$ effect was evident during the period of June 1992 to May 2015 for the PSEI index.

Pinto (2015) by analyzing the rates of return (in the period of 1949-2001) noticed them falling on the fourth day of the month on the Tokyo Stock Exchange (TSE) and proved that the effect of bad luck numbers started to lose its power in the middle of 1980s. This can be explained by the increasing internationalization of equity investors in Japan. More foreigners, less prone to be influenced by Japanese folk beliefs, trading the TSE , diluted the strength of the Fourth Day effect. Haggard (2015) examining the stock returns impact of days with lucky numbers on Chinese equity market, demonstrated a lucky number date trading strategy for the Shenzhen market. Suganda et al. (2018) studying the influence of the scared days between daily cycles in Georgian calendar and Javanese calendar on the basis of rates of return of Jakarta Composite Index in the period of January 2009 - June 2016, found that investment decision were sill influenced by superstition, leading to behavior biases. Bhattacharya et al. (2017) proved on the example of Taiwan Futures Exchange that the individual investors, but not institutional investors, submitted disproportionately more limit orders at" 8 " than at " 4 ". This imbalance, defined as superstitions index for each investors seed to be positively correlated with trading losses. Superstitious investors lose more money because of their bad market timing and stale orders.

Taking into consideration the fact that some traders try to avoid making investments during unlucky days, it seems reasonable to study the returns during trading days before and after Friday the $13^{\text {th }}$ (Peltomaki $\&$ Peni, 2010; Peltomaki \& Vahamaa, 2014). Stefanescu and Dumitriu (2018) on the basis of the daily rates of return for three American stock indexes: S\&P 500, FJIA and NASDAQ, found no evidence for the traditional form of the Friday the $13^{\text {th }}$ effect, but thy concluded that the returns during two trading days before Friday the $13^{\text {th }}$ tended to be higher than the average returns, while the returns during one or two trading days after, resulted to be lower than the average. 


\section{Methodology}

The research is divided into five parts. The calculation were proceeded concerning constituents of the following world stock indexes (in brackets the number of the analyzed companies): CAC40 (39), DAX (30), DJIA (30), FTSE30 (30), FTSE MIBTEL (37), NIKKEI225 (223) and SENSEX (30), e.g. for 419 equities. In case of the indexes CAC40 and NIKKEI225 indexes, one and two of their components, respectively were removed due to the short listing period. The list of analyzed companies and the first dated included in the analysis are presented in the Table A1 and Table A2 (Appendix).The last session considered in the process of calculating rates of return was 30.06.2018.

In case of two populations, the null hypothesis $H_{0}$ and alternative hypothesis $H_{l}$ regarding equality of rates of return in two populations, can be formulated as follows:

where:

$$
\begin{aligned}
& H_{0}: E\left(\overline{r_{1}}\right)=E\left(\overline{r_{2}}\right) \\
& H_{1}: E\left(\overline{r_{1}}\right) \neq E\left(\overline{r_{2}}\right)
\end{aligned}
$$

$\overline{r_{1}}$-average rate of return in the first population,

$\overline{r_{2}}$-average rate of return in the second population.

On the basis of two independent populations of rate of returns, which sizes are equal $n_{l}$ and $n_{2}$, respectively, the hypotheses $H_{0}$ and $H_{l}$ should be tested with the use of statistics $z$ (Defusco et al., 2001, p. 335):

$$
\mathrm{z}=\frac{\overline{\mathrm{r}_{1}}-\overline{\mathrm{r}_{2}}}{\sqrt{\left(\frac{\mathrm{s}_{1}^{2}}{\mathrm{n}_{1}}+\frac{\mathrm{s}_{2}^{2}}{\mathrm{n}_{2}}\right)}}
$$

where:

$S_{1}^{2}$ - variance of rates of return in the first population,

$S_{2}^{2}$ - variance of rates of return in the second population,

$n_{1}$ - number of observations in the first population,

$n_{2}$ - number of observations in the second population.

In case when the population variances are unknown and cannot be assumed that they are equal, the number of degrees of freedom will be expressed according to the following formula (Defusco et al., 2001, p. 335):

$$
d f=\frac{\left(\frac{s_{1}^{2}}{n_{1}}+\frac{s_{2}^{2}}{n_{2}}\right)^{2}}{\frac{\left(s_{1}^{2} / n_{1}\right)^{2}}{n_{1}}+\frac{\left(s_{2}^{2} / n_{2}\right)^{2}}{n_{2}}}
$$

In the following part of the analysis, parametric tests of Kruskal-Wallis will be implemented. The Kruskal-Wallis test statistics is given by (Vargha \& Delaney, 1998):

$$
H=\frac{12}{N(N+1)} \sum_{i=1}^{i=g} n_{i} \bar{r}_{i}^{2}-3(N+1)
$$

where:

$N$ - total number of observations across all groups,

$\bar{r}_{i}=\frac{\sum_{j=1}^{n_{i}} r_{i j}}{n_{i}}-$ average rank of all observations in group $i$,

$n_{i}$ - number of observation in group $i$,

$r_{i j}$ - the rank (among all observations) of observation $j$ from group $i$,

In all analyzed cases, the $p$-values will be calculated. If the $p$-value is less or equal to 0.05 , then the hypothesis $H_{0}$ is rejected in favor of the hypothesis $H_{l}$. Otherwise, there is no reason to reject hypothesis $H_{0}$. i \{ldisplaystyle i\}

For each of the analyzed indexes the following rates of return will be calculated:

1) Close - Close: $\frac{C_{t}-C_{t-1}}{C_{t-1}}$ (last session close versus previous session close),

2) Overnight: $\frac{o_{t}-C_{t-1}}{C_{t-1}}$ (last session open versus previous session close), 
3) Open - Open: $\frac{o_{t}-o_{t-1}}{O_{t-1}}$ (last session open versus previous session open),

4) Open - Close: $\frac{C_{t}-O_{t}}{O_{t}}$ (last session close versus last session open),

where:

$C_{t}$ - closing price in the period $t$,

$C_{t-1}$ - closing price in the period $t-1$,

$O_{t}$-open price in the period $t$,

$O_{t-1}-$ open price in the period $t-1$,

The daily rates of return were calculated for all companies included in the analyzed indices. Then the tests for equality of two average rates of return in two populations were exemplified in the following cases:

1) The first population: $13^{\text {th }}$ day of the month, the second population: all remaining sessions,

2) The first population: Friday the $13^{\text {th }}$ day of the month, the second population: all remaining sessions,

3) The first population: Tuesday the $13^{\text {th }}$ day of the month, the second population: all remaining sessions,

4) The first population: $4^{\text {th }}$ day of the month, the second population: all remaining sessions,

5) The first population: Friday the $13^{\text {th }}$ day of the month, the second population: all remaining Fridays. In the second part of the fifth part, the test for equality of two average rates of return were computed under the assumption that the first group of data consists of rates of return for sessions falling on Tuesday the $13^{\text {th }}$ and the second group is composed of rates of return for all remaining Tuesdays. In this part only close-close rates of return were taken into consideration.

\section{Analysis of Results}

\subsection{CAC40 Index}

The results of testing a zero hypothesis with the use of average rates of returns for two different populations permit to draw the following conclusions:

\subsubsection{Z-Statistics}

The null hypothesis regarding equality of two average rates of return was rejected for the following equities ( $p$-value shown in parenthesis):

a) $13^{\text {th }}$, Close-close: Air Liquide (0.0474) and Sanofi (0.0064),

b) $13^{\text {th }}$, Open-open: Arcelormittal (0.0127),

a) $13^{\text {th }}$, Open-close: EDF (0.0437), Sanofi (0.0335),

b) Friday the $13^{\text {th }}$, Close-close: $\operatorname{EDF}(0.0417)$,

c) Friday the $13^{\text {th }}$, Open-open: Airbus (0.0068),

d) Friday the $13^{\text {th }}$, Open-close: $\operatorname{EDF}(0.0167)$,

e) Tuesday the $13^{\text {th }}$, Close-close: Orange (0.0337), Renault (0.0089), Sanofi (0.0412), Technip (0.0485)

f) Tuesday the $13^{\text {th }}$, Open-close: Danone (0.0273), Michelin (0.0488), Orange (0.0300), Peugeot $(0.0287)$ and Renault (0.0010),

g) $4^{\text {th }}$, Close-close: Veolia Environment $(0.0101)$,

h) $4^{\text {th }}$, Open-close: Carrefour (0.0273), Veolia Environment (0.0107),

i) Friday the $13^{\text {th }}$ vs Fridays, Close-lose: $\operatorname{EDF}(0.0048)$,

j) Tuesday the $13^{\text {th }}$ vs Tuesdays, Close-Close: Michelin (0.0227), Orange (0.0336), Peugeot (0.0095), Renault (0.0004) and Schneider Electric (0.0293).

The results of calculating $p$ values for returns of the CAC40 components with the use of the $\mathrm{Z}$ statistic test are presented as an example in the Table A3 (Appendix). For the Kruskal-Wallis test, as well as for other index components, the calculation were proceeded in the same way. 


\subsubsection{Kruskal-Wallis Test}

The null hypothesis regarding equality of two average rates of return was rejected for the following equities (p-value shown in parenthesis):

a) $13^{\text {th }}$, Close-close: LVHM (0.0363), Solvey (0.0450),

b) $13^{\text {th }}$, Overnight: Bouygues (0.0295),

c) $13^{\text {th }}$, Open-open: Arcelormittal (0.0200), Nokia Oyj (0.0421), Safran (0.0247),

d) Friday the $13^{\text {th }}$, Close-close: Sanofi (0.0075),

e) Friday the $13^{\text {th }}$, Open-open: Arcellormittal (0.0200), Nokia Oyj (0.0421), Safran (0.0247),

f) Tuesday the $13^{\text {th }}$, Close-close: Orange (0.0127), Renault (0.0028), Sanofi (0.0179),

g) Tuesday the $13^{\text {th }}$, Open-close: Orange (0.0330), Peugot (0.0467), Renault (0.0109),

h) $4^{\text {th }}$, Close-close: Cap Gemini (0.0073), LVHM (0.0499), Peugeot (0.0468), Veolia Environment (0.0102),

i) $4^{\text {th }}$, Open-close: Cap Gemini (0.0315), Veolia Environment (0.0190),

j) Friday the $13^{\text {th }}$ vs Fridays, Close-close: EDF (0.0262),

k) Tuesday the $13^{\text {th }}$ vs Tuesdays, Close-close: Orange (0.0475), Peugeot $(0.0190)$, Renault (0.0048), Schneider Electric (0.0212).

In all other cases, there was no reason to reject the null hypothesis in favor of the alternative hypothesis.

\subsubsection{Confirmation of the Results Obtained with Z-Statistics by the Kruskal-Wallis Test}

The null hypothesis was rejected using of two tests (the $\mathrm{Z}$ statistics and Kruskal-Wallis) for the following companies:

a) EDF: Friday the $13^{\text {th }}$ vs Fridays, Close-close,

b) Orange: Tuesday the $13^{\text {th }}$, Close-close and Open-close, Tuesday the $13^{\text {th }}$ vs Tuesdays, Close-close,

c) Peugeot: Tuesday the $13^{\text {th }}$, Open-close and Tuesday the $13^{\text {th }}$ vs Tuesdays, Close-close,

d) Renault: Tuesday the $13^{\text {th }}$, Close-close and Open-close, Tuesday the $13^{\text {th }}$, Close-close,

e) Sanofi: Tuesday the $13^{\text {th }}$, Close-close,

f) Schneider Electric: Tuesday the $13^{\text {th }}$ vs Tuesdays, Close-close,

g) Veoila Environement: $4^{\text {th }}$ Close-close and Open-close.

For many analyzed companies the results obtained with the $\mathrm{Z}$ statistics were not confirmed by the Kruskal-Wallis test. Thus, in case of the French stock index, the effect of Tuesday the $13^{\text {th }}$ was the strongest and was mainly observed for the Close-close and Open-close rates of return. This is a result that deserves attention, especially since the perception of the Tuesday the $13^{\text {th }}$ as a unfortunate date is a characteristic for Spain and Hispanic countries. On the French market one could rather expect the dominance of the effect of the Friday the $13^{\text {th }}$ than Tuesday the $13^{\text {th }}$.

\subsection{DAX Index}

The results of testing a zero hypothesis with the use of average rates of returns for two different populations permit to draw the following conclusions:

\subsubsection{Z-Statistics}

The null hypothesis regarding equality of two average rates of return was rejected for the following equities ( $p$-value shown in parenthesis):

a) $13^{\text {th }}$, Overnight: Infineon Tech (0.0488), Muench Rueckvers (0.0230),

b) Friday the $13^{\text {th }}$, Close-close: Continental (0.0281), Deutsche Boerse (0.0000), Vonovia (0.0217),

c) Friday the $13^{\text {th }}$, Overnight: Deutsche Boerse $(0.0053)$,

d) Friday the $13^{\text {th }}$, Open-open: Deutsche Boerse (0.0000), Siemens (0.0351),

e) Friday the $13^{\text {th }}$, Open-close: Continental $(0.0450)$, Deutsche Boerse $(0.0024)$, Vonovia $(0,0240)$,

f) Tuesday the $13^{\text {th }}$, Close-close: Daimler (0.0493), Heilderbergcement (0.0209), Infineon Tech (0.0456), Muench Rueckvers (0.0372),

g) Tuesday the $13^{\text {th }}$, Open-close: Frasen Med. (0.0463), Heilderbergcement (0.0196), 
h) $4^{\text {th }}$, Close-close: Fresenius (0.0134), Prosieben Sat (0.0335),

i) $4^{\text {th }}$, Overnight: Continental (0.0287),

j) $4^{\text {th }}$, Open-open: Continental (0.0084),

k) $4^{\text {th }}$, Open-close: Continental (0.0084),

1) Friday the $13^{\text {th }}$ vs Fridays: Continental (0.0414), Vonovia (0.0345),

m) Tuesday the $13^{\text {th }}$ vs Tuesdays: Heilderbergcement (0.0135).

\subsubsection{Kruskal-Wallis Test}

The null hypothesis regarding equality of two average rates of return was rejected for the following equities ( $p$-value shown in parenthesis):

a) $13^{\text {th }}$, Close-close: Bay Motoren (0.0450), Thyssen Krupp (0.0182),

b) $13^{\text {th }}$, Open-open: BASF (0.0468), Daimler (0.0278), Deutsche Bank (0.0142), Siemens (0.0170),

c) $13^{\text {th }}$, Open-close: Bay Motoren (0.0398),

d) Friday the $13^{\text {th }}$, Overnight: EON (0.0118),

e) Tuesday the $13^{\text {th }}$, Close-close: Comerzbank (0.0231), Daimler (0.0239), Frasen Med (0.0477), Heilderbergcement (0.0030), Muench Rueckvers (0.0075), SAP (0.0365),

f) Tuesday the1 $3^{\text {th }}$, Open-open: Lined (0.0349),

g) Tuesday the $13^{\text {th }}$, Open-close: Heilderbergcement $(0.0330)$,

h) $4^{\text {th }}$, Close-close: Fresenius $(0.0132)$,

i) $4^{\text {th }}$, Open-open: Continental (0.0030),

j) $4^{\text {th }}$, Open-close: Fresenius $(0.0015)$,

k) Tuesday the $13^{\text {th }}$ vs Tuesdays: Heilderbergcement (0.0214).

In all other cases, there was no reason to reject the null hypothesis in favor of the alternative hypothesis.

\subsubsection{Confirmation of the Results Obtained with Z-Statistics by the Kruskal-Wallis Test}

The null hypothesis was rejected with the use of two tests (the $\mathrm{Z}$ statistics and Kruskal-Wallis) for the following companies:

a) Continental: $4^{\text {th }}$, Open-open,

b) Dimler: Tuesday the $13^{\text {th }}$, Close-close,

c) Fresenius: $4^{\text {th }}$, Close-close and Open-close,

d) Heilderbergcement: Tuesday the $13^{\text {th }}$, Close-close and Open-close, $13^{\text {th }}$ Tuesday vs Tuesdays, Close-close,

e) Muench Rueckvers: Tuesday the $13^{\text {th }}$, Close-close.

The strongest effect on the German stock exchange was Tuesday the $13^{\text {th }}$, which preceded the effect of the $4^{\text {th }}$ day of the month. The first effect was registered mainly for the rates of return: Close-close. On the German market, as in case of France, more expected was the dominance of the Friday the $13^{\text {th }}$ effect, which was not recorded. The effect of the $4^{\text {th }}$ day of the month is expected mainly in Asian markets.

\subsection{DJIA Index}

The results of testing a zero hypothesis with the use of average rates of returns for two different populations permit to draw the following conclusions:

\subsubsection{Z-Statistics}

The null hypothesis regarding equality of two average rates of return was rejected for the following equities (p-value shown in parenthesis):

a) $13^{\text {th }}$, Close-close: Apple (0.0106), Boeing (0.0411),

b) $13^{\text {th }}$, Overnight: Apple (0.0063), Caterpillar (0.0282),

c) $13^{\text {th }}$ Open-open: Home Depot (0.0140),

d) $13^{\text {th }}$, Open-Close: Boeing (0.0202), Home Depot (0.0381), 
e) Friday the $13^{\text {th }}$, Overnight: $3 \mathrm{M}(0.0494)$, Boeing (0.0240), JP Morgan (0.0237),

f) Friday the $13^{\text {th }}$, Open-open: Johnson $\&$ Johnson (0.0040), Pfizer (0.0216),

g) Tuesday the $13^{\text {th }}$, Close-close: Apple (0.0489),

h) Tuesday the $13^{\text {th }}$, Overnight: Chevron (0.0407),

i) Tuesday the $13^{\text {th }}$, Open-open: Caterpillar (0.0195),

j) Tuesday the $13^{\text {th }}$, Open-close: $3 \mathrm{M}(0.0419)$, Du Point (0.0410), Home Depot (0.0142), Wall-Mart (0.0244),

k) $4^{\text {th }}$, Close-close: General-Electric (0.0174), IBM (0.0381), McDonalds (0.0480),

l) $4^{\text {th }}$, Open-open: Procter \& Gamble (0.0311), United Health (0.0064), United Technologies (0.0297),

m) $4^{\text {th }}$, Open-close: General Electric (0.0379),

n) Tuesday the $13^{\text {th }}$ vs Tuesdays, Close-close: Home Depot (0.0099).

\subsubsection{Kruskal-Wallis Test}

The null hypothesis regarding equality of two average rates of return was rejected for the following equities ( $p$-value shown in parenthesis):

a) $13^{\text {th }}$, Close-close: $3 \mathrm{M}(0.0104)$, Chevron (0.0445),

b) $13^{\text {th }}$, Overnight: $3 \mathrm{M}(0.0334)$, Boeing (0.0341), JP Morgan (0.0146), Verizon (0.0341),

c) $13^{\text {th }}$, Open-open: Johnson \& Johnson (0.0066), Pfizer (0.0352),

d) $13^{\text {th }}$, Open-close: $3 \mathrm{M}(0.0379)$,

e) Friday the $13^{\text {th }}$, Close-close: Apple (0.0287), Chevron (0.0140), Coca-Cola (0.0447),

f) Friday the $13^{\text {th }}$, Overnight: Apple (0.0088),

g) Friday the $13^{\text {th }}$, Open-open: Nike (0.0020),

h) Friday the $13^{\text {th }}$, Open-close: Chevron (0.0056),

i) Tuesday the $13^{\text {th }}$, Close-close: Apple (0.0333), Coca-Cola (0.0069),

j) Tuesday the $13^{\text {th }}$, Overnight: Chevron $(0.0231)$,

k) Tuesday the $13^{\text {th }}$, Open-open: Caterpillar (0.0420),

1) Tuesday the $13^{\text {th }}$, Open-close: Coca-Cola (0.0307), Home Depot (0.0241), Wall-Mart (0.0405),

m) $4^{\text {th }}$, Close-close: Chevron (0.0315), General Electric (0.0381),

n) $4^{\text {th }}$, Overnight: Home Depot (0.0030), Nike (0.0449), United Health (0.0210),

o) $4^{\text {th }}$, Open-open: Microsoft (0.0188), Procter \& Gamble (0.0211), United Health (0.0094), United Technologies (0.0176),

p) $4^{\text {th }}$, Open-close: JP Morgan (0.0411),

q) Friday the $13^{\text {th }}$ vs Fridays, Close-close: $3 \mathrm{M}(0.0442)$,

r) Tuesday the $13^{\text {th }}$ vs Tuesdays: Coca-Cola (0.0282), Home Depot (0.0310).

4.3.3 Confirmation of the Results Obtained with Z-Statistics by the Kruskal-Wallis Test

In all other cases, there was no reason to reject the null hypothesis in favor of the alternative hypothesis.

The null hypothesis was rejected with the use of two tests (the $\mathrm{Z}$ statistics and Kruskal-Wallis) for the following companies:

a) Apple: Tuesday the $13^{\text {th }}$, Close-close,

b) Caterpillar: Tuesday the $13^{\text {th }}$, Overnight,

c) Chevron: Tuesday the $13^{\text {th }}$, Overnight,

d) General Electric: $4^{\text {th }}$, Close-close,

e) Home Depot: Tuesday the $13^{\text {th }}$, Open-close and Tuesday the $13^{\text {th }}$ vs Tuesdays, Close-close,

f) Procter \& Gamble: $4^{\text {th }}$, Open-open,

g) United Health: $4^{\text {th }}$, Open-open, 
h) United Technologies: $4^{\text {th }}$, Open-open,

i) Wall-Mart: Tuesday the $13^{\text {th }}$, Open-close.

On the American market, the two dominant effects were observed: Tuesday the $13^{\text {th }}$ as well as the $4^{\text {th }}$ day of the month. The first of them is associated mainly with Spanish and Latin culture, and the second with Asian. There was no Friday the $13^{\text {th }}$ effect, characteristic mainly for the European cultural circle. Tuesday the $13^{\text {th }}$ effect was registered mainly for Overnight and Close-close rates of return and the $4^{\text {th }}$ day of the month effect for Open-open rates of return.

\subsection{FTSE30}

The results of testing a zero hypothesis with the use of average rates of returns for two different populations permit to draw the following conclusions:

\subsubsection{Z-Statistics}

The null hypothesis regarding equality of two average rates of return was rejected for the following equities ( $p$-value shown in parenthesis):

a) $13^{\text {th }}$, Close-close: GlaxoSmithKline (0.0461),

b) $13^{\text {th }}$, Overnight: GKN (0.0449), Reckit Benckiser (0.0433),

c) $13^{\text {th }}$, Open-open: Reckit Benckiser (0.0261),

d) $13^{\text {th }}$, Open-close: $3 \mathrm{I}(0.0222)$, BAE System (0.0044),

e) Friday the $13^{\text {th }}$, Close-close: Burberry (0.0286), Experian (0.0259),

f) Friday the $13^{\text {th }}$, Overnight: Land Sec. (0.0307), Lloyds Banking (0.0358), Smith (0.0243), Unilever (0.0206),

g) Friday the $13^{\text {th }}$, Open-open: BP (0.0272), Diageo (0.0031), Unilever (0.0489),

h) Friday the $13^{\text {th }}$, Open-close: British American Tobacco (0.0142),

i) Tuesday the $13^{\text {th }}$, Close-close: 3I (0.0088), BAE System (0.0221), Glaxo Smith Kline (0.0456), Land Sec (0.0113), Prudential (0.0286), Tate and Lyle (0.0025), Wolseley (0.0222),

j) Tuesday the $13^{\text {th }}$, Overnight: RSA Insurance (0.0440),

k) Tuesday the $13^{\text {th }}$, Open-open: Marks \& Spencer (0.0419),

1) Tuesday the $13^{\text {th }}$, Open-close: 3I (0.0424), BAE System (0.0003), Experian (0.0060), Glaxo Smith Kline (0.0405), Vodafone (0.0447), Wolseley (0.0219),

$\mathrm{m}) 4^{\text {th }}$, Close-close: INTL Consolidated Airlines (0.0481), Reckit Benckiser (0.0179),

n) $4^{\text {th }}$, Overnight: BT Group (0.0209), Man Group (0.0207), Vodafone (0.0339),

o) $4^{\text {th }}$, Open-open: Associated British Food (0.0185), Man Group (0.0220), Tate and Lyle (0.0304),

p) $4^{\text {th }}$, Open-close: Reckit Benckiser (0.0280),

q) Friday the $13^{\text {th }}$ vs Fridays, Close-close: British American Tobacco (0.0160),

r) Tuesday the $13^{\text {th }}$ vs Tuesdays, Close-close: 3 I (0.0162), BAE System (0.0004), Experian (0.0035), Prudential (0.0319), Royal Bank of Scotland (0.0411), Vodafone (0.0443), Wolseley (0.0170).

\subsubsection{Kruskal-Wallis Test}

The null hypothesis regarding equality of two average rates of return was rejected for the following equities ( $p$-value shown in parenthesis):

a) $13^{\text {th }}$, Close-close: British American Tobacco (0.0374), Burberry (0.0365), Experian (0.0368),

b) $13^{\text {th }}$, Overnight: Tesco (0.0416), Unilever (0.0332),

c) $13^{\text {th }}$, Open-open: BP (0.0349), Diageo (0.0026), Experian (0.0395), Tesco (0.0189), Unilever (0.0308),

d) $13^{\text {th }}$, Open-close: Associated British Food (0.0492), British American Tobacco (0.0099),

e) Friday the $13^{\text {th }}$, Close-close: Glaxo Smith Kline (0.0238),

f) Friday the $13^{\text {th }}$, Overnight: Diageo (0.0281), Reckit Benckier (0.0291),

g) Friday the $13^{\text {th }}$, Open-close: $3 \mathrm{I}(0.0254)$, BAE System (0.0096),

h) Tuesday the $13^{\text {th }}$, Close-close: 3I (0.0211), Glaxo Smith Kline (0.0225), Land Sec. (0.0421), Prudential 
(0.0456), RSA Insurance (0.0429), Tate and Lyle (0.0098), Wolseley (0.0036),

i) Tuesday the $13^{\text {th }}$, Open-open: Marks \& Spencer (0.0442),

j) Tuesday the $13^{\text {th }}$, Open-close: BAE System (0.0009), Experian (0.0136), Glaxo Smith Kline (0.0241), Royal Bank Scotland (0.0352), Wolseley (0.0125),

k) $4^{\text {th }}$, Overnight: Lloyds Banking (0.0446), Man Group (0.0467),

1) $4^{\text {th }}$, Open-open: Associated British Food (0.0268), Tate and Lyle (0.0249),

m) Friday the $13^{\text {th }}$ vs Fridays, Close-close: British American Tobacco (0.0129),

n) Tuesday the $13^{\text {th }}$ vs Tuesdays, Close-close: BAE System (0.0010), Experian (0.0087), Glaxo Smith Kline (0.0334), Lloyds Banking (0.0249), Royal Bank of Scotland (0.0113), Wolseley (0.0081).

In all other cases, there was no reason to reject the null hypothesis in favor of the alternative hypothesis.

4.4.3 Confirmation of the Results Obtained with Z-Statistics by the Kruskal-Wallis Test

The null hypothesis was rejected with the use of two tests (the $\mathrm{Z}$ statistics and Kruskal-Wallis) for the following companies:

a) 3I: Tuesday the $13^{\text {th }}$, Close-close,

b) Associated British Food: $4^{\text {th }}$, Open-open,

c) BAE System: Tuesday the $13^{\text {th }}$, Open-close and Tuesday the $13^{\text {th }}$ vs. Tuesdays, Close-close

d) British American Tobacco: Friday the $13^{\text {th }}$ vs Fridays, Close-close,

e) Experian: Tuesday the $13^{\text {th }}$, Open-close and Tuesday the $13^{\text {th }}$ vs Tuesdays, Close-close,

f) Glaxo Smith Kline: Tuesday the $13^{\text {th }}$, Close-close and Open-close,

g) Land Sec.: Tuesday the $13^{\text {th }}$, Close-close,

h) Man Group: $4^{\text {th }}$, Overnight,

i) Marks and Spencer: Tuesday the $13^{\text {th }}$, Open-open,

j) Prudential: Tuesday the $13^{\text {th }}$, Close-close,

k) Royal bank of Scotland: Tuesday the $13^{\text {th }}$ vs Tuesdays, Close-close,

1) Tate and Lyle: Tuesday the $13^{\text {th }}$, Close-close, $4^{\text {th }}$, Open-open,

m) Wolseley: Tuesday the $13^{\text {th }}$, Close-close, Open-close and Tuesday the $13^{\text {th }}$ vs Tuesdays, Close-close.

On the British market, just like on the American market, the following effects dominated: Tuesday the $13^{\text {th }}$ as well as the $4^{\text {th }}$ day of the month. The first one was observed most frequently for Clos-close and Open-open rates of return and the second for Open-open returns. The Friday the $13^{\text {th }}$ effect occurred but sporadically.

\subsection{FTSE MIBTEL}

The results of testing a zero hypothesis with the use of average rates of returns for two different populations permit to draw the following conclusions:

\subsubsection{Z-Statistics}

The null hypothesis regarding equality of two average rates of return was rejected for the following equities ( $p$-value shown in parenthesis):

a) $13^{\text {th }}$, Open-open: FIAT $(0.0373)$,

b) $13^{\text {th }}$, Open-open: Intesa San Paolo (0.0070), Unicredit (0.0466),

c) $13^{\text {th }}$, Open-close: Brembo (0.0310),

d) Friday the $13^{\text {th }}$, Open-open: Ferrari (0.0036),

e) Friday the $13^{\text {th }}$, Open-close: CHN Industrial (0.0005), FIAT (0.0094), Telecom Italia (0.0158),

f) Tuesday the $13^{\text {th }}$, Close-close: Buzzi Unicem (0.0131), FIAT (0.0184),

g) Tuesday the $13^{\text {th }}$, Overnight: Buzzi Unicem (0.0233), Tenaris (0.0151),

h) Tuesday the $13^{\text {th }}$, Open-close: FIAT (0.0319), Recordati (0.0256), Salvatore Ferragamo (0.0069),

i) $4^{\text {th }}$, Close-close: Luxottica $(0.0383)$, 
j) $4^{\text {th }}$, Overnight: ENI (0.0223), Terna Rete (0.0145), Unione di Banche (0.0418),

k) $4^{\text {th }}$, Open-open: CHN Industrial (0.0091),

1) $4^{\text {th }}$, Open-close: Brembo (0.0253), Luxottica (0.0159), SNAM (0.0306), Terna Rete $(0.0074)$,

m) Friday the $13^{\text {th }}$ vs Fridays, Close-close: CHN Industrial (0.0028), FIAT (0.0076), Telecom Italia (0.0128),

n) Tuesday the $13^{\text {th }}$ vs Tuesdays, Close-close: FIAT (0.0491), Recordati (0.0243), Salvatore Ferragamo (0.0087), Terna Rete $(0.0320)$,

\subsubsection{Kruskal-Wallis Test}

The null hypothesis regarding equality of two average rates of return was rejected for the following equities ( $p$-value shown in parenthesis):

a) $13^{\text {th }}$, Open-close: FIAT (0.0130), Telecom Italia $(0.0390)$

b) Friday the $13^{\text {th }}$, Close-close: FIAT (0.0415),

c) Friday the $13^{\text {th }}$, Overnight: Intesa San Paolo (0.0200), Salvatore Ferragamo (0.0347),

d) Friday the $13^{\text {th }}$, Open-open: Brembo (0.0466), SNAM (0.0316),

e) Friday the $13^{\text {th }}$, Open-close: FIAT $(0.0443)$,

f) Tuesday the $13^{\text {th }}$, Close-close: Buzzi Unicem (0.0373), ENI (0.0399), FIAT (0.0224),

g) Tuesday the $13^{\text {th }}$, Overnight: Azymut (0.0480), Buzzi Unicem (0.0109), Tenaris (0.0114),

h) Tuesday the $13^{\text {th }}$, Open-open: Luxottica $(0.0086)$,

i) Tuesday the $13^{\text {th }}$, Open-close: Recordati (0.0418),

j) $4^{\text {th }}$, Close-close: Brembo (0.0295),

k) $4^{\text {th }}$, Overnight: A2A (0.0116), BPER Banca $(0.0270)$,

l) $4^{\text {th }}$, Open-open: CHN Industrial (0.0361),

m) $4^{\text {th }}$, Open-close: Banco Popolare (0.0485), Brembo (0.0324), Davide Campari (0.0349), Luxottica (0.0292), SNAM (0.0330), Tenaris (0.0195), Terna Rete (0.0043),

n) Friday the $13^{\text {th }}$ vs Fridays, Close-close: FIAT (0.0171), Telecom Italia (0.0470),

o) Tuesday the $13^{\text {th }}$ vs Tuesdays, Close-close: Recordati (0.0413).

In all other cases, there was no reason to reject the null hypothesis in favor of the alternative hypothesis.

4.5.3 Confirmation of the Results Obtained with Z-Statistics by the Kruskal-Wallis Test

The null hypothesis was rejected with the use of two tests (the $\mathrm{Z}$ statistics and Kruskal-Wallis) for the following companies:

a) Brembo: $4^{\text {th }}$, Open-close,

b) Buzzi Unicem: Tuesday the $13^{\text {th }}$, Close-close, Overnight,

c) CHN Industrial: $4^{\text {th }}$, Open-open,

d) FIAT: Friday the $13^{\text {th }}$, Open-close, Tuesday the $13^{\text {th }}$, Close-close, Friday the $13^{\text {th }}$ vs Fridays, Close-close,

e) Luxottica: $4^{\text {th }}$, Open-close,

f) Recordati: Tuesday the $13^{\text {th }}$, Open-close, Tuesday the $13^{\text {th }}$ vs Tuesdays, Close-close,

g) SNAM: $4^{\text {th }}$, Open-close,

h) Telecom Italia, Friday the $13^{\text {th }}$ vs Fridays, Close-close,

i) Tenaris: Tuesday the $13^{\text {th }}$, Overnight,

j) Terna Rete: $4^{\text {th }}$, Open-close.

On the Italian market the two most dominant effects were: $4^{\text {th }}$ day of the month as well as Tuesday the $13^{\text {th }}$. The first one was registered mainly for Open-close rates of return, and the second for Close-close returns. Friday the $13^{\text {th }}$ effect occurred but sporadically.

\subsection{NIKKEI}

The results of testing a zero hypothesis with the use of average rates of returns for two different populations permit 
to draw the following conclusions:

\subsubsection{Z-Statistics}

The null hypothesis regarding equality of two average rates of return was rejected for the following equities ( $p$-value shown in parenthesis):

a) $13^{\text {th }}$, Close-close: Dainpn Sumi (0.0491), East Japan (0.0318), Fujitsu (0.0126), Kyocera (0.0053), Mitsumi Electr. (0.0484), NEC (0.0250), NTT Data (0.0144), Odakyu Elec. (0.0284), Resona Holdings (0.0213), Sharp (0.0271), Sotbank (0.0057), Taisei (0.0031), Takara (0.0304), TGK Insulators (0.0168), Toyota (0.0326), Trend Micro (0.0045), Yaskawa (0.0265),

b) $13^{\text {th }}$, Overnight: Ana Holdings (0.0324), Astellas Pharmas (0.0392), Dainpn Sumi (0.0094), East Japan (0.0361), Hitach Const (0.0187), Kaima (0.0285), Kansai Elec. (0.0350), KDDI (0.0287), Softbank (0.0174), Trend Micro (0.0080), Yahoo Japan (0.0220),

c) $13^{\text {th }}$, Open-open: Astallas Pharmas (0.0071), Daikin Ind. (0.0200), Hitach Const. (0.0202), OJI Holdings (0.0351), Softbank (0.0391), Tokyo Ele. PWR (0.0139), Trend Micro (0.0031), Yahoo Yapan (0.0013), Yokogawa (0.0386),

d) $13^{\text {th }}$, Open-close: Citizen Watch (0.0236), Fujitsu (0.0187), Kyocera (0.0181), NH Foods (0.0418), NTT Data (0.0348), Odaky Elec. (0.0088), Oki Elec. (0.0284), Resona Holdings (0.0299), Sharp (0.0163), Taisei (0.03030), TGK Insulators (0.0223), Yamato Holdings (0.0310), Yaskawa (0.0422),

e) Friday the $13^{\text {th }}$, Close-close: Astellas Pharmas (0.0105), Da Nip (0.0050), Daikin Ind. (0.0123), Daiwa Securities (0.0261), East Japan (0.0197), Fujitsu (0.0127), Heiwa R. (0.0292), Hitachi Const. (0.0471), Hitachi Zosen (0.0437), Kaima (0.0248), Kyocer (0.0320), Marui Group (0.0430), Meidensha (0.0164), NEC (0.0369), Nissan (0.0263), Nisshin Steel (0.0331), NTT Data (0.0008), NTT Docomo (0.0370), Osaka Gas (0.0423), Resona Holdings (0.0076), Sharp (0.0115), Softbank (0.0186), Suzuki (0.0382), Taiser (0.0150), Takara (0.0384), Toho SVC (0.0032), Toho Zinc (0.0081), Tokai Carbon (0.0232), Tokyo Dome (0.0044), Toto (0.0077), Trend Micro (0.0438),

f) Friday the $13^{\text {th }}$, Overnight: Ana Holdings (0.0352), Astellas Pharmas (0.0259), East Japan (0.0026), Mitsui (0.0389), Mitsumi Electr. (0.0490), Nippon Paper (0.0025), Nissan (0.0478), Toshiba (0.0439),

g) Friday the $13^{\text {th }}$, Open-open: Daikin Ind. (0.0053), Dainpn Sumi (0.0270),

h) Friday the $13^{\text {th }}$, Open-close: AEON (0.0209), Citizen Watch (0.0363), Comsys (0.0494), Daikin Ind. (0.0017), Heiwa R. (0.0277), Hitachi (0.0481), Hitachi Zosen (0.0056), Honda (0.0278), JTEKT (0.0448), Kyocera (0.0266), Meidensha (0.0099), Mitshubishi (0.0115), Mitshubishi Est (0.0324), Mitsui Eng. (0.0301), Nippon Paper (0.0034), Nippon Sheet GLS (0.0254), Nissan (0.0145), Nisshin Steel (0.0336), NTT Data (0.0024), NTT Docomo (0.0264), Resona Holdings (0.0280), Sharp (0.0001), Softbank (0.0007), Sumitomo Elec. (0.0214), Taiheyo Cement (0.0186), Taisei (0.0041), Takara (0.0075), TGK Insulators $(0.0198)$, Toho SVC (0.0345), Toho Zinc (0.0418), Tokyo Dome (0.0060), Toto (0.0162), Toyota Tsusho (0.0207),

i) Tuesday the $13^{\text {th }}$, Close-close: Canon (0.0382), Credit Saison (0.0071), Daikin Ind. (0.0038), Dainpn Sumi $(0,0210)$, Fujitsu (0.0054), JGC (0.0034), KDDI (0.0379), Kyocera (0.0061), Nitto Denko (0.0448), Nissan (0.0045), NTT (0.0239), NTT Data (0.0369), Odakyu Elec. (0.0476), OJI Holdings (0.0058), Secom (0,0011), Softbank (0.0239), Takeda (0.0009), TGK Insulators (0.0262), Tokuyama (0.0093), Tokyo Electron (0.0208), Tokyo Marine (0.0462), Tokyo Seikan (0.0219), Trend Micro (0.0355),

j) Tuesday the $13^{\text {th }}$, Overnight: Ajinomoto (0.0254), Chubu Ele. (0.0331), Dainpn Suma (0.0206), Fujitsu (0.0393), Furukawa Elek. (0.0251), Inpex (0.0111), JGC (0.0071), Kaima (0.0259), Kansai Elec. (0.0026), Kuraray (0.0213), Nikkon (0.0387), Nippon Soda (0.0182), Nomura Holdigns (0.0016), Showa Denko (0.0321), Sky Perfect (0.0357), Takeda (0.0000), Trend Micro (0.0034),

k) Tuesday the $13^{\text {th }}$, Open-open: Bridgestone (0.0232), Denso (0.0327), Durukawa (0.0350), Fuji Film (0.0020), JGC (0.0457), Kansai Elec. (0.0463), Kyowa (0.0031), Meidensha (0.0451), Mitsubishi Elec. (0.0492), Mitsui (0.0365), Nikkon (0.0232), OJI Holdings (0.0085), Resona Holdings (0.0164), Shinsei Bank (0.0065), Sky Perfect (0.0009), Sumitomo Elec. (0.0328), Sumitomo Osaka (0.0065), Tokai Carbon (0.0235), Tokyo Ele. PWR (0.0050), Toshiba (0.0196), Toto (0.0239), Trend Micro (0.0456),

1) Tuesday the $13^{\text {th }}$, Open-Close: Ashi Group (0.0051), Credit Saison (0.0028), Fujitsu (0.0439), Kyocera (0.0187), Mitsumi Ele. (0.0333), NH Foods (0.0270), Nitto Denko (0.0494), Screen Holdings (0.0337), Secom (0.0004), Toho SVC (0.0408), Tokuyama (0.0150), Toyo Seikan (0.0161), Trend Micro (0.0134), 
m) $4^{\text {th }}$, Close-close: Astellas Pharmas (0.0435), Honda (0.0333), Konami (0.0100), Meiji Holdings (0.0225), NEC (0.0488), Sekisui (0.0183), Taisei (0.0048), Tokyo Marine (0.0176),

n) $4^{\text {th }}$, Overnight: Astellas Pharmas (0.0050), Canon (0.0193), Daichi Sankuyo (0.0498), Honda (0.0426), Inpex (0.0272), Konami (0.0040), Mineb Mitsumi (0.0380), Mitsui (0.0477), Sekisui (0.0038), Seven \& I (0.0366), Shinsei Bank (0.0429), Sumitomo (0.0216), T\&D Holdings (0.0221),

o) $4^{\text {th }}$, Open-open: Astellas Pharmas (0.0428), Inpex (0.0071), Mitsub Logistic (0.0437), Nippon Paper (0.0168), NTN (0.0128), Sekisui (0.0141), Seven \& I (0.0150), Shimizu (0.0416), Takashimaya (0.0471), Yamato Holdings (0.0073),

p) $4^{\text {th }}$, Open-close: Hitachi Const. (0.0186), KDDI (0.0252), Taisei (0.0174), Toyobo (0.0457),

q) Friday the $13^{\text {th }}$ vs Fridays: AEON (0.0173), Citizen Watch (0.0450), Comsys (0.0347), Daikin Ind. (0.0026), Daiwa Sec. (0.0280), Dowa Holdings (0.0489), Fujitsu (0.0150), Fukuoka Fin. (0.0224), Heiwa R. (0.0286), Hitachi Zosen (0.0070), Honda (0.0190), JFE Holdings (0.0436), JTEKT (0.0306), Kyocera (0.0309), Matsui Sec. (0.0400), Mazda (0.0073), Meidensha (0.0042), Mitsubishi (0.0086), Mitsubishi Est. (0.0369), Mitsui Eng. (0.0259), Nippon Sheet GLS (0.0139), Nisshin Steel (0.0389), NTT Data (0.0012), NTT Docomo (0.00186), OKI Elec. (0.0383), Resona Holdings (0.0141), Sharp (0.0002), Softbank (0.0006), Sumco (0.0395), Sumitomo (0.0162), Sumitomo Elec. (0.0324), Taiheyo Cement $(0.0130)$, Taisei $(0.0028)$, Takara (0.0087), TGK Insulators (0.0098), Tokyo Dome (0.0044), Tokyo Marine (0.0456), Toto (0.0228), Toyota Tsusho (0.0153), Trend Micro (0.0345),

r) Tuesday the $13^{\text {th }}$ vs Tuesdays: Ashi Group (0.0033), Credit Saison (0.0074), Kyocera (0.0444), NH Foods (0.0296), Secom (0.0013), Teijin (0.0384), Tokuyama (0.0468), Toyo Seikan (0.0437),

\subsubsection{Kruskal-Wallis Test}

The null hypothesis regarding equality of two average rates of return was rejected for the following equities (p-value shown in parenthesis):

a) $13^{\text {th }}$, Close-close: Astellas Pharmas (0.0061), Da Nip (0.0087), East Japan (0.0092), Fujitsu (0.0375), Heiwa R. (0.0280), Kaima (0.0203), Marui Group (0.0253), Mitsui Fudosan (0.0334), Mnisshin (0.0365), NTT Data (0,0052), NTT Docomo (0.0042), Resona Holdings (0.0198), Softbank (0.0415), Suzuki (0.0341), Taisei (0.0231), Takara (0.0297), Toho SVC (0.0367), Tokai Carbon (0.0474), Tokyo Dome (0.0136), Toshiba (0.0420), Toto (0.0182), Trend Micro (0.0368),

b) $13^{\text {th }}$, Overnight: East Japan (0.0073), Mitsui (0.0125),

c) $13^{\text {th }}$, Open-open: Daikin Ind. (0.0164),

d) $13^{\text {th }}$, Open-close: Citizen Watch (0.0175), Daikin Ind. (0.0197), Dowa Holdings (0.0390), Heiwa R. (0.0405), Hitachi Zosen (0.0115), Kyocera (0.0223), Meidensha (0.0293), Mitsubishi (0.0405), Mitsubishi Est. (0.0426), Mitsui Fudosan (0.0084), Nippon Sheet GLS (0.0211), NTT Data (0,0030), NTT Docomo (0.0041), Resona Holdings (0.0095), Sharp (0.0001), Softbank (0.0023), Suzuki (0.0292), Taiheyo Cement (0.0278), Taisei (0.0017), Takara (0.0181), Tokyo Dome (0.0150), Toto (0.0108), Toyo Seikan (0.0184), Toyota Tsusho (0.0370), Trend Micro (0.0145),

e) Friday the $13^{\text {th }}$, Close-close: Central Japan (0.0317), Dainpn Sumi (0.0394), East Japan (0.0239), Fujitsu (0.0369), NTT Data (0.0152), Odakyu Elec. (0.0230), Sharp (0.0371), Softbank (0.0232), Taisei (0.0134), Trend Micro (0.0078),

f) Friday the $13^{\text {th }}$, Overnight: Astellas Pharmas (0.0310), Daipn Sumi (0.0387), East Japan (0.0321), Hitachi Const. (0.0223), Kansai Elec. (0.0373), Taisei (0.0480), Tokuyama (0.0192), Trend Micro (0.0324),

g) Friday the $13^{\text {th }}$, Open-open: Astellas Pharmas (0.0054), Daikin Ind. (0.0457), Hitachi Const. (0.0416), Meijin Holdings (0.0219), OJI Holdings (0.0139), Softbank (0.0245), Tokyo Ele. PWWR (0.0204), Tokyo Gas (0.0215), Trend Micro (0.0124), Yahoo Japan (0.0112),

h) Friday the $13^{\text {th }}$, Open-close: Citizen Watch (0.0368), Odakyu Elec. (0.0083), Oki Elec. (0.0469), Sharp (0.0153), Taisei (0.0381), Yamato Holdings (0.0485),

i) Tuesday the $13^{\text {th }}$, Close-close: Credit Saison (0.0241), Daikin Ind. (0.0227), Dainpn Sumi (0.0255), Fujitsu (0.0136), JGC (0.0197), Kyocera (0.0044), NTT Data (0.0338), Odakyu Elec. (0.0255), Oki Elec. (0.0495), OJI Holdings (0.0315), Pioneer (0.0197), Showa Denko (0.0308), Softbank (0.0331), Takeda (0.0039), Toho SVC (0.0218), Tokuyama (0.0105), Toyo Seikan (0.0397), Trend Micro (0.0467), Yamaha (0.0479),

j) Tuesday the $13^{\text {th }}$, Overnight: Ajinomoto (0.0276), Dainpn Sumi (0.0330), Inpex (0.0314), JGC (0.0245), 
Kansai Elec. (0.0055), Mitsubishi (0.0392), Nippon Soda (0.0267), Nomura Holdings (0.0038), Takeda (0.0003), Trend Micro (0.0123),

k) Tuesday the $13^{\text {th }}$, Open-open: Astellas Pharmas (0.0434), Bridgestone (0.0490), Chlyoda (0.0365), Durukawa (0.0381), Fuji Film (0.0027), Komatsu (0.0380), Kyowa (0.0024), Meidensha (0.0367), Mitsubishi Elec. (0.0459), Mitsui Ord (0.0297), Nikkon (0.0291), Nomura Holdings (0.0256), OJI Holdings (0.0174), Shinsei Bank (0.0450), Showa Denko (0.0184), Sky Perfect (0.0049), Sumitomo Elec. (0.0385), Sumitomo Osaka (0.0247), Tokuyama (0.0024), Tokyo Ele. PWR (0.0094), Tosoh (0.0227),

1) Tuesday the $13^{\text {th }}$, Open-close: Ashi Group (0.0132), Credit Saison (0.0112), Daikin Ind. (0.0219), Kyocera (0.0313), NH Foods (0.0379), Nichirei (0.0380), Screen Holdings (0.0478), Secom (0.0006), Tokuyama (0.0423), Toyo Seikan (0.0134),

m) $4^{\text {th }}$, Close-close: Astellas Pharmas (0.0413), Fuji Heavy Ind. (0.0436), Honda (0.0333), Konami (0.0136), NEC (0.0386), Nippon Light Metal (0.0160), Taisei (0.0165), Tokyo Marine (0.0463),

n) $4^{\text {th }}$, Overnight: Astellas Pharmas (0.0196), Konami (0.0115), Mitsubishi Motor (0.0350), Sapporo Holdings (0.0404), Sekisui (0.0092), Seven \& I (0.0490),

o) $4^{\text {th }}$, Open-open: Cobe Steel (0.0351), Eisai (0.0453), Inpex (0.0133), Mitsub Logistic (0.0180), Mitsubishi Elec. (0.0245), Mitsubishi Motor (0.0170), Mitsui Fudosan (0.0320), Nippon Paper (0.0355), NSK (0.0136), NTN (0.0053), Obayashi (0.0278), Sekisui (0.0062), Seven \& I (0.0193), Shimizu (0.0130), Takashimaya (0.0261), Tobu RW (0.0453), Tokyo Fudosan (0.0155), Tokyo Ord. (0.0453), Yamato Holdings (0.0042),

p) $4^{\text {th }}$, Open-close: Htiachi Const. (0.0177), Kyocera (0.0465), Meiji Holdings (0.0427), Nippon Light Metal (0.0261), Taisei (0.0411),

q) Friday the $13^{\text {th }}$ vs Fridays: Citizen Watch (0.0246), Comsys (0.0460), Daikin Ind. (0.0294), Dowa Holdings (0.0242), Fujitsu (0.0361), Heiwa R. (0.0496), Hitachi Zosen (0.0177), JTEKT (0.0413), Keio Ord. (0.0498), Kyocera (0.0332), Mazda (0.0358), Meidensha (0.0136), Mitsubishi (0.0308), Mitsui Fudosan (0.0145), Nippon Sheet GLS (0.0125), NTT Data (0.0017), NTT Docomo (0.0033), Resona Holdings (0.0057), Sharp (0.0001), Softbank (0.0022), Suzuki (0.0265), Taiheyo Cement (0.0207), Taisei (0.0013), Takara (0.0213), TGK Insulators (0.0362), Tokyo Dome (0.0113), Toto (0.0152), Tokyo Seikan (0.0072), Toyota Tsusho (0.0323), Trend Micro (0.0348),

r) Tuesday the $13^{\text {th }}$ vs Tuesdays: Ashi Group (0.0114), Credit Saison (0.0216), Daikin Ind. (0.0436), NH Foods (0.0443), Nichirei (0.0395), Secom (0.0025), Sumitomo Osaka (0.0482), Tokyo Seikan (0.0435).

In all other cases, there was no reason to reject the null hypothesis in favor of the alternative hypothesis.

\subsubsection{Confirmation of the Results Obtained with Z-Statistics by the Kruskal-Wallis Test}

The null hypothesis was rejected with the use of two tests (the $\mathrm{Z}$ statistics and Kruskal-Wallis) for the following companies:

a) $13^{\text {th }}$, Close-close: East Japan, Fujitsu, NTT Data, Resna Holdings, Sharp, Soft Bank, Taisei, Takara

b) $13^{\text {th }}$, Overnight: East Japan,

c) $13^{\text {th }}$, Open-open: Daikin Ind.,

d) $13^{\text {th }}$, Open-close: Citizen Watch, Kyocera, NTT Data, Resona Holdings, Sharp, Taisei,

e) Friday the $13^{\text {th }}$, Close-close: East Japan, Fujitsu, NTT Data, Sharp, Softbank, Taisei, Terend Micro,

f) Friday the $13^{\text {th }}$, Overnight: Astellas Pharmas, East Japan,

g) Friday the $13^{\text {th }}$, Open-open: Daikin Ind.,

h) Friday the $13^{\text {th }}$, Open-close: Citizen Watch, Sharp, Taisei,

i) Tuesday the $13^{\text {th }}$, Close-close: Advantest, Credit Saison, Daikin Ind., Dainpn Sumi, Fujitsu, JGC, Kyocera, NTT Data, Odakyu Elec., OJI Holdings, Secom, Softbank, Takeda, Tokuyama, Toyo Seikan,

j) Tuesday the $13^{\text {th }}$, Overnight: Ajinomoto, Dainpn Sumi, JGC, Kansai Elec., Nippon Soda, Nomura Holdings, OJI Holdings, Takeda,

k) Tuesday the $13^{\text {th }}$, Open-open: Bridgestone, Durukawa, Fuji Film, Kyowa, Meidensha, Mitsubishi Elec., Nikkon, OJI Holdings, Shinsei Bank, Sky Perfect, Sumitomo Elec., Sumitomo Osaka, Tokyo Ele PWR,

1) Tuesday the $13^{\text {th }}$, Open-close: Ashi Group, Credit Saison, Kyocera, NH Foods, Screen Holdings, Secom, Tokuyama, Toyo Seikan, 
m) $4^{\text {th }}$, Close-close: Astellas Pharmas, Honda, Konami, NEC, Taisei, Tokyo Marine,

n) $4^{\text {th }}$, Overnight: Astellas Pharmas, Konami, Sekisui, Seven \& I,

o) $4^{\text {th }}$, Open-open: Inpex, Mitsub Logistic, Nippon Paper, NTN, Sekisui, Seven \& I, Shimizu, Takashimaya, Yamato Holdings,

p) $4^{\text {th }}$, Open-close: Hitachi Const., Taisei,

q) Friday the $13^{\text {th }}$ vs Fridays: Citizen Watch, Comsys, Daikin Ind., Dowa Holdings, Fujitsu, Heiwa R., Hitachi Zosen, JTEKT, Kyocera, Mazda, Meidensha, Mitsubishi, Nippon Sheet GLS, NTT Data, NTT Docomo, Resona Holdings, Sharp, Softbank, Taiheyo Cement, Taisei, Takara, TGK Insulators, Tokyo Dome, Toto, Toyota Tsusho,

r) Tuesday the $13^{\text {th }}$ vs Tuesdays: Ashi Group, Credit Saison, NH Foods, Secom, Toyo Seikan.

On the Japanese stock market the appearance of all types of effects was observed, both those related to the number 13 and the number 4 . Most often, the effects occurred for the following returns: Close-close $\left(13^{\text {th }}\right.$ day of the month, Friday the $13^{\text {th }}$ and Tuesday the $13^{\text {th }}$ ), Open-open (Tuesday the $13^{\text {th }}$ and $4^{\text {th }}$ day of the month) and Open-close $\left(13^{\text {th }}\right.$ day of the month).

\subsection{SENSEX}

The results of testing a zero hypothesis with the use of average rates of returns for two different populations permit to draw the following conclusions:

\subsubsection{Z-Statistics}

The null hypothesis regarding equality of two average rates of return was rejected for the following equities ( $p$-value shown in parenthesis):

a) $13^{\text {th }}$, Open-open: Bharat Airtel (0.0291),

b) Friday the $13^{\text {th }}$, Close-close: Bharat Heavy (0.0114), Gail India (0.0012), Infosys (0.0140), Vedanta (0.0136), Wipro (0.0224),

c) Friday the $13^{\text {th }}$, Overnight: Bajaj Auto (0.0008),

d) Friday the $13^{\text {th }}$, Open-close: Asian paints (0.0303), Bharat Heavy (0.0165), Hindalco India (0.0193), Icici Bank (0.0071), Infosys (0.0132), Tata Consultancy (0.0050), Vedanta (0.0472), Wipro (0.0133),

e) Tuesday the $13^{\text {th }}$, Close-close: Housing Development (0.0437), Icici Bank (0.0206), Mahindra \& Mahindra (0.0479), NTPC (0.0234),

f) Tuesday the $13^{\text {th }}$, Open-open: Gail India (0.0375),

g) Tuesday the $13^{\text {th }}$, Open-close: Icici Bank (0.0121), NTPC (0.0076),

h) $4^{\text {th }}$, Close-close: State Bank of India (0.0125),

i) $4^{\text {th }}$, Open-open: Asian Paints (0.0236), Bharat Heavy (0.0004),

j) $4^{\text {th }}$, Open-close: State Bank of India (0.0296), Tata Steel (0.0300),

k) Friday the $13^{\text {th }}$ vs Fridays: Asian Paints (0.0473), Bharat Heavy (0.0184), Hindlaco India (0.0134), Icici Bank (0.0120), Infosys (0.0101), Tata Consultancy (0.0072), Vedanta (0.0475), Wipro (0.0187),

1) Tuesday the $13^{\text {th }}$ vs Tuesdays: Icici Bank (0.0064), Mahindra \& Mahindra (0.0283), NTPC $(0.0054)$,

\subsubsection{Kruskal-Wallis Test}

The null hypothesis regarding equality of two average rates of return was rejected for the following equities (p-value shown in parenthesis):

a) $13^{\text {th }}$, Close-close: Bharat Heavy (0.0130), Bharti Airtel (0.0342), Gail India (0.0029), Infosys (0.0447), Larsen $\&$ Toubro (0.0391), State Bank of India (0.0459), Vedanta (0.0234),

b) $13^{\text {th }}$, Overnight: Bajaj Auto (0.0258),

c) $13^{\text {th }}$, Open-close: Bharat Heavy (0.0204), Bharti Airtel (0.0465), Hindalco India (0.0124), Icici Bank (0.0137), Infosys (0.0110), State Bank of India (0.0357), Tata Consultancy (0.0341), Wipro (0.0086),

d) Friday the $13^{\text {th }}$, Open-open: Bharti Airtel (0.0329), Mahindra \& Mahindra (0.0427), Tata Steel (0.0284),

e) Tuesday the $13^{\text {th }}$, Close-close: Icici Bank (0.0084), NTPC (0.0336), 
f) Tuesday the $13^{\text {th }}$, Open-close: Icici Bank (0.0037), NTPC (0.0069),

g) $4^{\text {th }}$, Close-close: State Bank of India (0.0110), Tata Motors (0.0341),

h) $4^{\text {th }}$. Overnight: Cipla (0.0248), Dr Reddy's Laboratories (0.0050), Oil and Natural Gas (0.0100),

i) $4^{\text {th }}$, Open-open: Asian Paints (0.0066), Bharat Heavy (0.0002), Cipla (0.0014), Maruti Suzuki (0.0183),

j) $4^{\text {th }}$, Open-close: Hindalco India (0.0336), State Bank of India (0.0221), Tata Steel (0.0321),

k) Friday the $13^{\text {th }}$ vs Fridays, Close-close: Asian Paints (0.0435), Bharat Heavy (0.0257), Hindalco India (0.0063), Icici Bank (0.0199), Infosys (0.0083), State Bank of India (0.0392), Tata Consultancy (0.0294), Wipro (0.0130),

1) Tuesday the $13^{\text {th }}$ vs Tuesdays, Close-close: Housing Development (0.0360), Icici Bank (0.0028), NTPC (0.0052),

In all other cases, there was no reason to reject the null hypothesis in favor of the alternative hypothesis.

4.7.3 Confirmation of the Results Obtained with Z-Statistics by the Kruskal-Wallis Test

The null hypothesis was rejected with the use of two tests (the $\mathrm{Z}$ statistics and Kruskal-Wallis) for the following companies:

a) Asian Paints: $4^{\text {th }}$, Open-open, Friday the $13^{\text {th }}$ vs Fridays, Close-close,

b) Bharat Heavy: $4^{\text {th }}$, Open-open, Friday the $13^{\text {th }}$ vs Fridays, Close-close,

c) Hindalco India: Friday the $13^{\text {th }}$ vs Fridays, Close-close,

d) Icici Bank: Tuesday the $13^{\text {th }}$, Close-close, Open-close, Friday the $13^{\text {th }}$ vs Fridays, Close-close, Tuesday the $13^{\text {th }}$ vs Tuesdays, Close-close,

e) Infosys: Friday the $13^{\text {th }}$ vs Fridays, Close-close,

f) NTPC: Tuesday the $13^{\text {th }}$, Close-close, Open-close, Tuesday the $13^{\text {th }}$ vs Tuesdays, Close-close,

g) State Bank of India: $4^{\text {th }}$, Close-close, Open-close,

h) Tata Consultancy: Friday the $13^{\text {th }}$ vs Fridays, Close-close,

i) Tata Steel: $4^{\text {th }}$, Open-close,

j) Wipro: Friday the $13^{\text {th }}$ vs Fridays, Close-close.

On the Indian stock market, just like on Japanese market, were registered all types of effects, related to the number 13 (Friday the $13^{\text {th }}$ and Tuesday the $13^{\text {th }}$ ) and the number 4 . The only exception is the effect of the $13^{\text {th }}$ day of the month that was not present. The observed effects most often occurred for the following returns: Close-close (Friday the $13^{\text {th }}$ and Tuesday the $13^{\text {th }}$ ), Open-open and Open-close (in both cases: $4^{\text {th }}$ day of the month).

\section{Conclusions}

The aim of this study was to determine the prevalence of the calendar effect in case of "the unfortunate dates effect", on the example of 7 world equity indexes components. Analysis of the effects of seasonality included an examination of the rates of return calculated for four approaches:
a) Close - close
b) Overnight
c) Open - open
d) Open - close

In all these cases the statistical equality of one-session rates of return for two population were calculated for:

a) Sessions falling on the $13^{\text {th }}$ day of the month vs all other sessions (first part),

b) Sessions falling on Friday the $13^{\text {th }}$ vs all other sessions (second part),

c) Sessions falling on Tuesday the $13^{\text {th }}$ vs all other sessions (third part),

d) Sessions falling on the $4^{\text {th }}$ day of month vs all other sessions (fourth part),

In the fifth part the statistical equality of one-session rates of return for the population of Friday the $13^{\text {th }}$ and the population of other Fridays were compared. The following part of the fifth part of the paper consists of the analysis of equality of rates of return for the sessions falling on Tuesday the $13^{\text {th }}$ vs rates of return calculated for all remaining Tuesdays. This is the first study known to the author that takes into account other rates of return than 
Close-close.

Calculations proceeded in this paper indicate the presence of "the unfortunate days effect" - the results are presented in Table 1, Table 2 and Table 3. The frequency of cases when $p$ values were lower than 0.05 for $\mathrm{Z}$ statistics as well as for Kruskal-Wallis tests, was the highest for Tuesday the $13^{\text {th }}$ (Close-close), followed by Tuesday the $13^{\text {th }}$ (Open-close), $4^{\text {th }}$ (Open-open), except CAC40 index and Friday the $13^{\text {th }}$ vs Fridays (Close-close), except DAX and DJIA indexes - see Figure 1. In case of the Nikkei index "the unfortunate days effect" was registered also for the following returns: $13^{\text {th }}$ day of the month (Open-close and Close-close) as well as for Tuesday the $13^{\text {th }}$ (Overnight and Open-open).

Table 1. Number of "the unfortunate day effects", calculated for the analyzed equity indexes components with the use of two statistical tests: $\mathrm{Z}$ statistics test and Kruskal-Wallis test (in brackets)

\begin{tabular}{|c|c|c|c|c|c|c|c|c|c|c|c|c|c|c|c|c|c|c|}
\hline \multirow{2}{*}{$\frac{\text { Index }}{\text { Index }}$} & \multicolumn{4}{|c|}{$13^{\text {th }}$ day of the month } & \multicolumn{4}{|c|}{ Friday the $13^{\text {th }}$} & \multicolumn{4}{|c|}{ Tuesday the $13^{\text {th }}$} & \multicolumn{4}{|c|}{$4^{\text {th }}$ day of the month } & \multirow{2}{*}{$\begin{array}{c}\text { Friday the } \\
13^{\text {th }} \text { vs } \\
\text { C-C }\end{array}$} & \multirow{2}{*}{$\begin{array}{l}\text { Tuesday } \\
\text { the } 13^{\text {th }} \text { vs } \\
\text { C-C }\end{array}$} \\
\hline & C-C & OV & $\mathrm{O}-\mathrm{O}$ & $\mathrm{O}-\mathrm{C}$ & C-C & OV & $\mathrm{O}-\mathrm{O}$ & $\mathrm{O}-\mathrm{C}$ & C-C & OV & $\mathrm{O}-\mathrm{O}$ & $\mathrm{O}-\mathrm{C}$ & C-C & OV & $\mathrm{O}-\mathrm{O}$ & $\mathrm{O}-\mathrm{C}$ & & \\
\hline CAC40 & $2(2)$ & $0(1)$ & $1(3)$ & $2(0)$ & $1(1)$ & $0(0)$ & $1(3)$ & $1(0)$ & $4(3)$ & $0(0)$ & $0(0)$ & $5(3)$ & $1(4)$ & $0(0)$ & $0(0)$ & $2(2)$ & $1(1)$ & $5(4)$ \\
\hline DAX & $0(2)$ & $2(0)$ & 0 (4) & $0(1)$ & $3(0)$ & $1(1)$ & $2(0)$ & $3(0)$ & $4(6)$ & $0(0)$ & $0(1)$ & $2(1)$ & $2(1)$ & $1(0)$ & $1(1)$ & $1(1)$ & $2(0)$ & $1(1)$ \\
\hline DJIA & $2(2)$ & $2(4)$ & $1(2)$ & $2(1)$ & $0(3)$ & $3(1)$ & $2(1)$ & $0(1)$ & $1(2)$ & $1(1)$ & $1(1)$ & $4(3)$ & $3(2)$ & $0(3)$ & $3(4)$ & $1(1)$ & $0(1)$ & $1(2)$ \\
\hline FTSE30 & $1(3)$ & $2(2)$ & $1(5)$ & $2(2)$ & $2(1)$ & $4(2)$ & $3(0)$ & $1(2)$ & 7 (7) & $1(0)$ & $1(1)$ & $6(5)$ & $2(0)$ & $3(2)$ & $3(2)$ & $1(0)$ & $1(1)$ & 7 (6) \\
\hline \multicolumn{19}{|l|}{ FTSE } \\
\hline MIBTEL & $1(0)$ & $2(0)$ & $1(0)$ & $0(2)$ & $0(1)$ & $0(2)$ & $1(2)$ & $3(1)$ & $2(3)$ & $2(3)$ & $0(1)$ & $3(1)$ & $1(1)$ & $3(2)$ & $1(1)$ & $4(7)$ & $3(2)$ & $4(1)$ \\
\hline NIKKEI & $17(22)$ & $11(2)$ & $9(1)$ & $13(25) 3$ & $31(10)$ & $8(8)$ & $2(10)$ & $33(6)$ & $23(19)$ & $17(10)$ & $22(21)$ & $13(10)$ & $8(8)$ & $13(6)$ & $10(19)$ & $4(5)$ & $40(30)$ & $8(8)$ \\
\hline SENSEX & $0(7)$ & $0(1)$ & $1(0)$ & $0(8)$ & $5(0)$ & $1(0)$ & $0(3)$ & $8(0)$ & $4(2)$ & $0(0)$ & $1(0)$ & $2(2)$ & $1(2)$ & $0(3)$ & $2(4)$ & $2(3)$ & $8(8)$ & $3(3)$ \\
\hline
\end{tabular}

Source: own calculation

Table 2. Number of cases when $p$ values were lower than 0.05 at the same time for two tests: $\mathrm{Z}$ statistics and Kruskal-Wallis

\begin{tabular}{|c|c|c|c|c|c|c|c|c|c|c|c|c|c|c|c|c|c|c|}
\hline \multirow[t]{2}{*}{ Index } & \multicolumn{4}{|c|}{$\begin{array}{l}13^{\text {th }} \text { day of the } \\
\text { month }\end{array}$} & \multicolumn{4}{|c|}{ Friday the $13^{\text {th }}$} & \multicolumn{4}{|c|}{ Tuesday the $13^{\text {th }}$} & \multicolumn{4}{|c|}{$4^{\text {th }}$ day of the month } & \multirow{2}{*}{$\begin{array}{c}\text { Friday the } \\
13^{\text {th }} \text { vs } \\
\text { C-C }\end{array}$} & \multirow{2}{*}{$\begin{array}{l}\text { Tuesday } \\
\text { the } 13^{\text {th }} \text { vs } \\
\text { C-C }\end{array}$} \\
\hline & $\mathrm{C}-\mathrm{C}$ & $\mathrm{OV}$ & $\mathrm{O}-\mathrm{O}$ & $\mathrm{O}-\mathrm{C}$ & $\mathrm{C}-\mathrm{C}$ & $\mathrm{OV}$ & $\mathrm{O}-\mathrm{O}$ & $\mathrm{O}-\mathrm{C}$ & $\mathrm{C}-\mathrm{C}$ & OV & $\mathrm{O}-\mathrm{O}$ & $\mathrm{O}-\mathrm{C}$ & $\mathrm{C}-\mathrm{C}$ & $\mathrm{OV}$ & $\mathrm{O}-\mathrm{O}$ & $\mathrm{O}-\mathrm{C}$ & & \\
\hline CAC40 & 0 & 0 & 0 & 0 & 0 & 0 & 0 & 0 & 3 & 0 & 0 & 3 & 1 & 0 & 0 & 1 & 1 & 4 \\
\hline DAX & 0 & 0 & 0 & 0 & 0 & 0 & 0 & 0 & 3 & 0 & 0 & 1 & 1 & 0 & 1 & 1 & 0 & 1 \\
\hline DJIA & 0 & 0 & 0 & 0 & 0 & 0 & 0 & 0 & 1 & 1 & 1 & 2 & 1 & 0 & 3 & 0 & 0 & 1 \\
\hline FTSE30 & 0 & 0 & 0 & 0 & 0 & 0 & 0 & 0 & 6 & 0 & 1 & 4 & 0 & 1 & 2 & 0 & 1 & 4 \\
\hline FTSE MIBTEL & 0 & 0 & 0 & 0 & 0 & 0 & 0 & 1 & 2 & 2 & 0 & 1 & 0 & 0 & 1 & 4 & 2 & 1 \\
\hline NIKKEI & 8 & 1 & 1 & 6 & 7 & 2 & 1 & 3 & 15 & 9 & 13 & 8 & 6 & 4 & 9 & 2 & 25 & 5 \\
\hline SENSEX & 0 & 0 & 0 & 0 & 0 & 0 & 0 & 0 & 2 & 0 & 0 & 2 & 1 & 0 & 2 & 2 & 7 & 2 \\
\hline
\end{tabular}

Source: own calculation.

Considering the quotient of (1) the number of cases when the null hypothesis was rejected at the same time with the use of the Kruskal-Wallis test and Z statistic and (2) the number of companies included in the analyzed index, the percentage ratio of these two variables can be calculated (see Table 3). The highest values of the percentage ration ( $\geq 10 \%$ ) were recorded for the following indexes (see Figure 5):
a) SENSEX $-23 \%$ (Friday the $13^{\text {th }}$ vs Fridays, C-C)
b) FTSE30 $-20 \%$ (Tuesday the $13^{\text {th }}$, C-C),
c) FTSE30 $-13.3 \%$ (Tuesday the $13^{\text {th }}$ vs Tuesdays, C-C),
d) FTSE30 $-13.3 \%$ (Tuesday the $13^{\text {th }}$, O-C)
e) NIKKEI $225-11.21 \%$ (Friday the $13^{\text {th }}$ vs Fridays, C-C)
f) FTSE MIBTEL $-10.81 \%\left(4^{\text {th }}\right.$, O-C $)$
g) DJIA $-10 \%\left(4^{\text {th }}, \mathrm{O}-\mathrm{O}\right)$. 
Table 3. Percentage of cases for each of analyzed indexes when $p$ values were lower than 0.05 at the same time for two kind of tests: $\mathrm{Z}$ statistics and Kruskal-Wallis (The results are derived from the Table 2 by dividing the number form the Table 2 by the umber of the analyzed components of each index)

\begin{tabular}{|c|c|c|c|c|c|c|c|c|c|c|c|c|c|}
\hline \multirow{3}{*}{ Index } & \multirow{2}{*}{$13^{\text {th }}$ day of the month } & \multirow{2}{*}{\multicolumn{2}{|c|}{ Friday the $13^{\text {th }}$}} & \multirow{2}{*}{\multicolumn{4}{|c|}{ Tuesday the $13^{\text {th }}$}} & \multirow{2}{*}{\multicolumn{4}{|c|}{$4^{\text {th }}$ day of the month }} & \multicolumn{2}{|c|}{ Friday the $13^{\text {th }}$ Tuesday the $13^{\text {th }}$} \\
\hline & & & & & & & & & & & & vs Fridays & vs Tuesdays \\
\hline & C-C OV O-O O-C C-C & $\mathrm{C}$ OV O-O C & $\mathrm{O}-\mathrm{C}$ & $\mathrm{C}-\mathrm{C}$ & OV & $\mathrm{O}-\mathrm{O}$ & $\mathrm{O}-\mathrm{C}$ & $\mathrm{C}-\mathrm{C}$ & OV & $\mathrm{O}-\mathrm{O}$ & $\mathrm{O}-\mathrm{C}$ & $\mathrm{C}-\mathrm{C}$ & $\mathrm{C}-\mathrm{C}$ \\
\hline $\mathrm{CAC} 40$ & $\begin{array}{llll}0.00 & 0.00 & 0.00 & 0.000 .00\end{array}$ & $\begin{array}{ll}0 & 0.000 .00\end{array}$ & 0.00 & 7.69 & 0.00 & 0.00 & 7.69 & 2.56 & 0.00 & 0.00 & 2.56 & 2.56 & 10.26 \\
\hline DAX & $\begin{array}{lllll}0.00 & 0.00 & 0.00 & 0.000 .00\end{array}$ & $\begin{array}{ll}0 & 0.000 .00\end{array}$ & 0.00 & 10.00 & 0.00 & 0.00 & 3.33 & 3.33 & 0.00 & 3.33 & 3.33 & 0.00 & 3.33 \\
\hline DJIA & 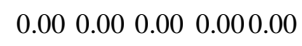 & $\begin{array}{ll}0 & 0.000 .00\end{array}$ & 0.00 & 3.33 & 3.33 & 3.33 & 6.67 & 3.33 & 0.00 & 10.00 & 0.00 & 0.00 & 3.33 \\
\hline FTSE30 & $\begin{array}{llll}0.00 & 0.00 & 0.00 & 0.000 .00\end{array}$ & $\begin{array}{ll}0 & 0.000 .00\end{array}$ & 0.002 & 20.00 & 0.00 & 3.33 & 13.33 & 0.00 & 3.33 & 6.67 & 0.00 & 3.33 & 13.33 \\
\hline FTSE MIBTEL & $\begin{array}{llll}0.00 & 0.00 & 0.00 & 0.000 .00\end{array}$ & $\begin{array}{ll}0 & 0.000 .00\end{array}$ & 2.70 & 5.41 & 5.41 & 0.00 & 2.70 & 0.00 & 0.00 & 2.70 & 10.81 & 5.41 & 2.70 \\
\hline NIKKEI & $\begin{array}{llll}3.59 & 0.45 & 0.45 & 2.693 .14\end{array}$ & $4 \quad 0.900 .45$ & 1.35 & 6.73 & 4.04 & 5.83 & 3.59 & 2.69 & 1.79 & 4.04 & 0.90 & 11.21 & 2.24 \\
\hline SENSEX & $\begin{array}{llll}0.00 & 0.00 & 0.00 & 0.000 .00\end{array}$ & $\begin{array}{ll}0 & 0.000 .00 \\
\end{array}$ & 0.00 & 6.67 & 0.00 & 0.00 & 6.67 & 3.33 & 0.00 & 6.67 & 6.67 & 23.33 & 6.67 \\
\hline
\end{tabular}

Source: own calculation.

Taking into account results of both tests, i.e. Kruskal-Wallis and $Z$ statistics, the calendar effect regarding rates of return of the $13^{\text {th }}$ day of the month was observed only on the Japanese market (for all calculated types of rates of return). Cultural differences between the analyzed markets would suggest the occurrence of the Tuesday the $13^{\text {th }}$ effect, possibly on European markets, on which the influence of Spanish investors can be noticed. Meanwhile, as a result of the conducted research, it was proved that this effect occurs on all analyzed markets, including Asian ones. The same applies to the effect of the $4^{\text {th }}$ day of the month, which should mainly be present in Asian markets. Meanwhile, it was registered in all analyzed markets. This fact entitles to the thesis about capital mobility in contemporary financial markets.

The calendar effects of returns calculated for Friday the $13^{\text {th }}$ in relation to other Fridays, were observed on all exchanges except for German and American, while the calendar effects of Tuesday the $13^{\text {th }}$ in relation to the other Tuesdays were registered for all analyzed equity exchanges.

Summing up the values in the individual rows of Table 3, another ranking can be created, e.g. ranking of unlucky number anomalies for all analyzed stock exchanges: DAX (26.67\%), CAC40 (33.33\%), DJIA (33.33\%), FTSE MIBTEL (37.84\%), NIKKEI 225 (56.05\%), SENSEX (60.00\%) and FTSE30 (63.33\%). Contrary to the expectations, the unlucky day effects were not the most commonly observed on the Asian Stock Exchanges but on the British Stock Exchange. "The unfortunate dates effect" was the most frequently observed for Tuesday and $13^{\text {th }}$ and then for the $4^{\text {th }}$ day of the month. Taking into consideration all types of analyzed returns (Close-close, Open-open, Open-close and Overnight), the most frequent effects were registered for the following returns: Close-close and for Open-close, with the exception of the $4^{\text {th }}$ day of the month effect, in which the order was changed.

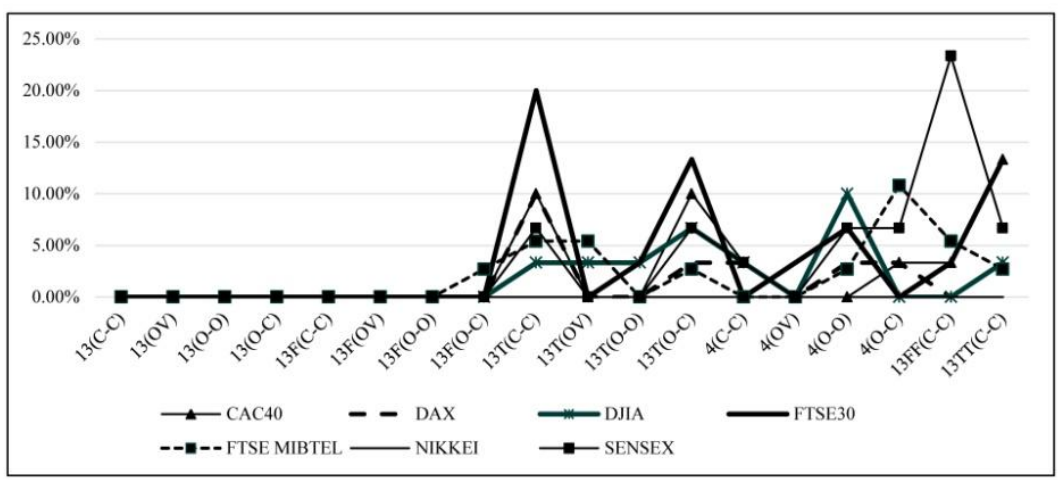

Figure 1. Frequency of cases when $p$ values were lower than 0.05 at the same time for two kind of tests

Source: own calculation.

Results obtained in the paper regarding the Friday the $13^{\text {th }}$ effect are consistent with those of Kolb and Rodriguez (1987). Notably the results do not support the outcomes reported by Agrawal and Tandon (1994), Coutts (1999) and Lucey (2000). Further research on the occurrence of "the unfortunate dates effect" in the financial markets should 
cover the currency and commodity market. The conducted studies proved the occurrence of "the unlucky day effect" not only in case of Close-close returns, but also in the remaining three that is Open-close, Open-open and Overnight.

The main limitation of this research is the range of data gained from the Reuters as well as the unequal intervals of observations for different equity indexes. The outcome may be regarded as a part of the ongoing discussions on the hypothesis of financial markets efficiency, which was introduced by Fama (1970). The results of the analysis entitles to the thesis about capital mobility in contemporary financial markets.

\section{References}

Agarwal, S., Jia, H., Haomijg, L., Png, I., \& Tien-Foo, S. (2014). Superstition and assets markets: Evidence from Singapore housing. SSRN Working Paper, 2416832. https://doi.org/10.2139/ssrn.2416832

Aggarval, R., \& Rivoli, P. (1989). Seasonal and day-of-the week effects in four emerging stock markets. Financial Review, 24, 541-550. https://doi.org/10.1111/j.1540-6288.1989.tb00359.x

Agrawal, A., \& Tandon, K. (1994). Anomalies or illusions? Evidence from stock markets in eighteen countries. Journal of International Money and Finance, 13, 83-106. https://doi.org/10.1016/0261-5606(94)90026-4

Auer, B., \& Rottman, H. (2014). Is there a Friday the $13^{\text {th }}$ effect in emerging Asian stock markets?. Journal of Behavioral and Experimental Finance, 1, 17-26. https://doi.org/10.1016/j.jbef.2014.01.001

Barone, E. (1990). The Italian stock market: Efficiency and calendar anomalies. Journal of Banking and Finance, 14, 493-510. https://doi.org/10.1016/0378-4266(90)90061-6

Bhattacharya, U., Kuo, W., Lin, T., \& Zhao, J. (2018). Do superstitious traders lose money? Management Science, 64(8). https://doi.org/10.1287/mnsc.2016.2701

Blacher, R. (1983). Clusters of disaster: Superstition and the physician. General Hospital Psychiatry, 5(4), 279-284. https://doi.org/10.1016/0163-8343(83)90007-5

Botha, F. (2013). Stock returns and Friday the $13^{\text {th }}$ effect in five African countries. African Review of Economics and Finance, 4(2), 247-253.

Boudreaux, D. (1995). The monthly effect in international stock markets: Evidence and implications. Journal of Financial and Strategic Decisions, 8(1), 15-20.

Boyle, G., Hagan, A., O'Connor, S., \& Whitwell, N. (2014). Emotion, fear and superstition in the New Zealand stock market. Working Paper New Zealand Institute for the Study of Competition and Regulation Inc.

Brown, P., \& Mitchel, J. (2008). Culture and stock price clustering: evidence from the Peoples' Republic of China. Pacific-Basin Finance Journal, 16(1), 95-120. https://doi.org/10.1016/j.pacfin.2007.04.005

Brown, P., Chua, A., \& Mitchell, J. (2002). The influence of cultural factors on price clustering: Evidence from Asia-Pacific stock markets. Pacific-Basin Finance Journal, 10(3), 307-332. https://doi.org/10.1016/S0927-538X(02)00049-5

Chamberlain, T., Cheung, C., \& Kwan, C. (1991). The Friday the Thirteenth effect: Myth or reality. Quarterly Journal of Business and Economics, 30(2), 111-117.

Chaundler, C. (1970). Every man's book of superstition. London: A. R. Mowbray and Co.

Chong, T., \& Du, X. (2009). The value of superstitions. Journal of Economic Psychology, 31, 293-309.

Chung, R., Darrat, A., \& Li, B. (2014). Superstitions and stock trading: Some new evidence. Journal of the Asia Pacific Economy, 19(4), 527-538. https://doi.org/10.1080/13547860.2014.920589

Coutts, J. (1999). Friday the thirteenth and the Financial Times industrial ordinary shares index 1935-94. Applied Economics Letters, 6(1), 35-37. https://doi.org/10.1080/135048599353843

Defusco, R., McLeavey, D., Pinto, J., \& Runkle, D. (2001). Quantitative methods for investment analysis. Baltimore: United Book Press.

Dyl, E., \& Maberly, E. (1988). The anomaly that isn't there: A comment on Friday the Thirteenth. Journal of Finance, 43(5), 1286-1295. https://doi.org/10.1111/j.1540-6261.1988.tb03971.x

Fama, E. (1970). Efficient capital markets; a review of theory and empirical work. Journal of Finance, 25(2), 383-417. https://doi.org/10.2307/2325486

Feltovich, N., \& Harbaugh, R. (2002). Too cool for school. Signaling and countersignaling. RAND Journal of Economics, 33(4), 630-649. https://doi.org/10.2307/3087478 
Fortin, N., Hill, A., \& Huang J. (2013). Superstition in the housing market. Economic Inquiry, 52(3), 974-985. https://doi.org/10.1111/ecin.12066

Fudenberg, D., \& Levine, D. (2006). Superstition and rational learning. American Economic Review, 96(3), 630-651. https://doi.org/10.1257/aer.96.3.630

$\mathrm{Gu}$, A. (2003). The declining January effect: Evidence from U.S. equity markets. Quarterly Review of Economics and Finance, 43, 395-404. https://doi.org/10.1016/S1062-9769(02)00160-6

Haggard, K. (2015). Stock returns in Chinese markets and lucky numbered days. Managerial Finance, 41(9), 925-939. https://doi.org/10.1108/MF-09-2014-0260

Hira, K., Fukui, T., Endoh, A., Rahman, M., \& Maekawa, M. (1998). Influence of superstition on the date of hospital discharge and medical cost in Japan, Retrospective and Descriptive Stud., British Medical Journal, - Clinical Research Edition, 317, 71-74, 1680-1682. https://doi.org/10.1136/bmj.317.7174.1680

Hirshleifer, D., Jian, M., \& Zhang, H. (2018). Superstition and financial decision making. Management Science, 64(1), 235-247. https://doi.org/10.1287/mnsc.2016.2584

Jiang, Y., Cho, A., \& Adaval, R. (2009). The unique consequences of feeling lucky: Implications for consumer behavior. Journal of Consume Psychology, 19(2), 171-184. https://doi.org/10.1016/j.jcps.2009.02.010

Kaku, K. (1972). Are physician sympathetic to superstition? A study of Hinoe-Uma. Social Biology, 19, 60-64. https://doi.org/10.1080/19485565.1972.9987966

Kaku, K. (1975). Increased induced Abortion rate in 1966, an aspect of Japanese folk superstition. Annals of Human Biology, 2(2), 111-115. https://doi.org/10.1080/03014467500000651

Kaku, K., \& Matsumoto, S. (1975). Influence of a folk superstition on fertility of Japanese in California and Hawaii. American Journal of Public Health, 65, 170-174. https://doi.org/10.2105/AJPH.65.2.170

Kalayaan, C. (2016). Superstition in the Philippine stock market. Review of Integrative Business and Economics Research, 5(2), 84-96.

Kato, K., Schwarz, S., \& Ziemba, W. (1990). Day of the weekend effects in Japanese stocks. Japanese Capital Markets. New York: Ballinger.

Kim, Y. (1979). Fertility of the Korean population in Japan influenced by a folk superstition in 1966. Journal of Biosocial Science, 11(4), 457-464. https://doi.org/10.1017/S0021932000012530

Kolb, E., \& Rodriguez, R. (1987). Friday the thirteenth: part VII - a note. Journal of Finance, 42(5), 1385-1387. https://doi.org/10.2307/2328534

Kramer, T., \& Block L. (2008). Conscious and non-conscious components of superstitious beliefs in judgment and decision-making. Journal of Consumer Research, 34(6), 783-793. https://doi.org/10.1086/523288

Latif, M., Arshad, S., Fatima, M., \& Rarooq, S. (2011). Market efficiency, market anomalies, causes, Evidences and some behavioral aspects of market anomalies. Research Journal of Finance and Accounting, 2(9-10), $1-14$.

Lepori, G. (2009). Dark omens in the sky: Do superstitious beliefs affect investment decisions? SSRN Working Paper 1428792, 2009. https://doi.org/10.2139/ssrn.1428792

Liu, W. (2013). Lunar calendar effect: evidence of the Chinese farmer's calendar on the equity markets in East Asia. Journal of the Asia-Pacific Economy, 18(4), 560-577. https://doi.org/10.1080/13547860.2013.803841

Lucey, B. (2000). Friday the $13^{\text {th }}$ and the philosophical basis of financial economics. Journal of Economics and Finance, 24(3), 294-301. https://doi.org/10.1007/BF02752610

Lucey, B. (2001). Friday the $13^{\text {th }}$ : International evidence. Applied Economics Letters, 8(9), 577-579. https://doi.org/10.1080/13504850010025664

Mills, T., \& Coutts, A. (1995). Calendar effects in the London Stock Exchange FT-SE Indices. European Journal of Finance, 1, 79-93. https://doi.org/10.1080/13518479500000010

Ng, T., Chong, T., \& Du, X. (2010). The value of superstitions. Journal of Economic Psychology, 31(3), 293-309. https://doi.org/10.1016/j.joep.2009.12.002

Patel, J. (2009). Recent evidence on Friday the thirteenth effect in U.S. stock returns. Journal of Business and Economics Research, 7(3), 55-58. https://doi.org/10.19030/jber.v7i3.2271

Peltomaki, J., \& Peni, E. (2010). Friday the thirteenth and the stock market. Manuscript. University of Vaasa. 
Peltomaki, J., \& Vahamma, E. (2014). Friday the thirteenth and stock index returns. Acta Wasaensia, 296, 393-407.

Pinto, J. (2015). Superstition and the stock market: evidence from Japanese stock returns. The $11^{\text {th }}$ International Conference on Knowledge-based Economy and Global Management, Tainan, Taiwan, 19-20 November, 2015.

Reilly, D., \& Stevenson, M. (2000). The effect of superstition on the day of discharge from maternity units in Northern Ireland: A Saturday flit is a short sit. Journal of Obstetrics and Gynaecology, 20, 139-142. https://doi.org/10.1080/01443610062887

Robiyanto, R., \& Puryandani, S. (2015). The Japanese lunar calendar's effect on Indonesian stock returns. Gadjah Mada International Journal of Business, 17(2), 125-137. https://doi.org/10.22146/gamaijb.6906

Robiyanto, R., Hersugondo, S., \& Puryandani, S. (2015). Chinese zodiac effect and precious metals returns of 1900-2015. International Journal of Applied Business and Economic Research, 13(5), 2759-2773.

Scalon, T., Luben, R., Scalon, F., \& Singleton, N. (1993). Is Friday the $13^{\text {th }}$ bad for your health? British Medical Journal, 307, 1584-1587. https://doi.org/10.1136/bmj.307.6919.1584

Schwert, W. (2002). Anomalies and market efficiency. Simon School of Business Working Paper no. FR 02-13, 2002. https://doi.org/10.2139/ssrn.338080

Shum, M., Sun, W., \& Ye, G. (2012). Superstition and 'lucky' apartments: Evidence from transaction-level data. Journal of Comparative Economics, 42(1), 109-117. https://doi.org/10.1016/j.jce.2013.10.001

Smirlock, M., \& Starks, M. (1986). Day-of-the-week and intraday effects in stock returns. Journal of Financial Economics, 17(1), 197-210. https://doi.org/10.1016/0304-405X(86)90011-5

Stefanescu, R., \& Dumitriu, R. (2018). Exploiting superstition in the investment strategies: Case of Friday the $13^{\text {th }}$ effect. Paper presented at the XI International \& Interdisciplinary Scientific Conference, Vanguard Scientific Instruments in Mamangement'2018, 11-16 September 2018, Ravda, Bulgaria. https://doi.org/10.2139/ssrn.3285485

Suganda, T., Sumargo, I., \& Robiyanto R. (2018). Superstitious behavior and stock returns: The case of Javanese traditional calendar. Kasetsart Journal of Social Sciences, 30, 1-6. https://doi.org/10.1016/j.kjss.2018.08.008

Sutheebanjard, P., \& Premchaiswadi W. (2010). Analysis of calendar effects: Day-of-the-week effect on the Stock Exchange of Thailand (SET). International Journal of Trade, Economics and Finance, 1(1), 2010-2023. https://doi.org/10.7763/IJTEF.2010.V1.11

Tsang ,E. (2004). Toward a scientific inquiry into superstitious business decision-making. Organization Studies, 25(6), 923-945. https://doi.org/10.1177/0170840604042405

USA Today. (2007). Some hotels don't skip the $13^{\text {th }}$ floor anymore. August 3, 2007.

Vargha, A., \& Delaney, H. (1998). Kruskal-Wallis test and stochastic homogeneity. Journal of Educational and Behavioral Statistics, 23(2), 170-192. https://doi.org/10.3102/10769986023002170

Zhang, Y., Risen, J., \& Hosey C. (2014). Reversing one's fortune by pushing away bad luck. Journal of Experimental Psychology, 143(3), 1171-1184. https://doi.org/10.1037/a0034023

\section{Appendix}

Table A1. Component of the following indexes included in the analysis: CAC40, DAX, DJIA, FTSE 30, FTSE MIBTEL and SENSEX

\begin{tabular}{|c|c|c|c|c|c|c|c|c|c|c|c|}
\hline CAC40 & $\begin{array}{c}\text { Date of first } \\
\text { quotation }\end{array}$ & DAX & $\begin{array}{c}\text { Date of first } \\
\text { quotation }\end{array}$ & DJIA & $\begin{array}{c}\text { Date of first } \\
\text { quotation }\end{array}$ & FTSE30 & $\begin{array}{c}\text { Date of first } \\
\text { quotation }\end{array}$ & $\begin{array}{c}\text { FTSE } \\
\text { MIBTEL }\end{array}$ & $\begin{array}{c}\text { Date of first } \\
\text { quotation }\end{array}$ & SENSEX & $\begin{array}{c}\text { Date of first } \\
\text { quotation }\end{array}$ \\
\hline \multirow[t]{2}{*}{ Accor } & 1985-01-07 & Adidas & $1995-11-17$ & $3 \mathrm{M}$ & 1970-01-02 & $3 \mathrm{I}$ & $1998-07-27$ & $\mathrm{~A} 2 \mathrm{~A}$ & $1998-07-22$ & Asian Paints & 1998-12-04 \\
\hline & & & & American & & Associated British & & & & & \\
\hline Air Liquide & 1985-01-07 & Alianz & 1991-04-05 & Express & 1972-01-07 & Food & $1998-07-28$ & Ansalo & 2006-03-29 & Bajaj Auto & $2008-05-26$ \\
\hline Airbus & 1999-06-04 & BASF & 1991-04-05 & Apple & 1984-09-07 & BAE System & $1998-07-28$ & Atlanta & $1998-10-16$ & Bharat Heavy & 1993-07-19 \\
\hline \multirow[t]{2}{*}{ Arcelormittal } & $1997-08-08$ & Bay Motoren & 1991-04-05 & Boeing & 1970-01-02 & BP & $1998-07-28$ & Autogrill & $1997-08-01$ & Bharti Airtel & $2002-02-18$ \\
\hline & & & & & & British American & & & & & \\
\hline AXA & 1985-01-07 & Bayer & 1991-04-05 & Caterpillar & 1970-01-02 & Tobacco & $1998-07-17$ & Ayzmut & 2004-07-07 & Cipla & 1993-07-13 \\
\hline BNP Paribas & 1993-10-18 & Beiersdorf & 2000-01-03 & Chevron & 1970-01-02 & BT Group & $1998-07-27$ & Banca Monte & $1999-06-25$ & Coal India & 2010-11-04 \\
\hline
\end{tabular}




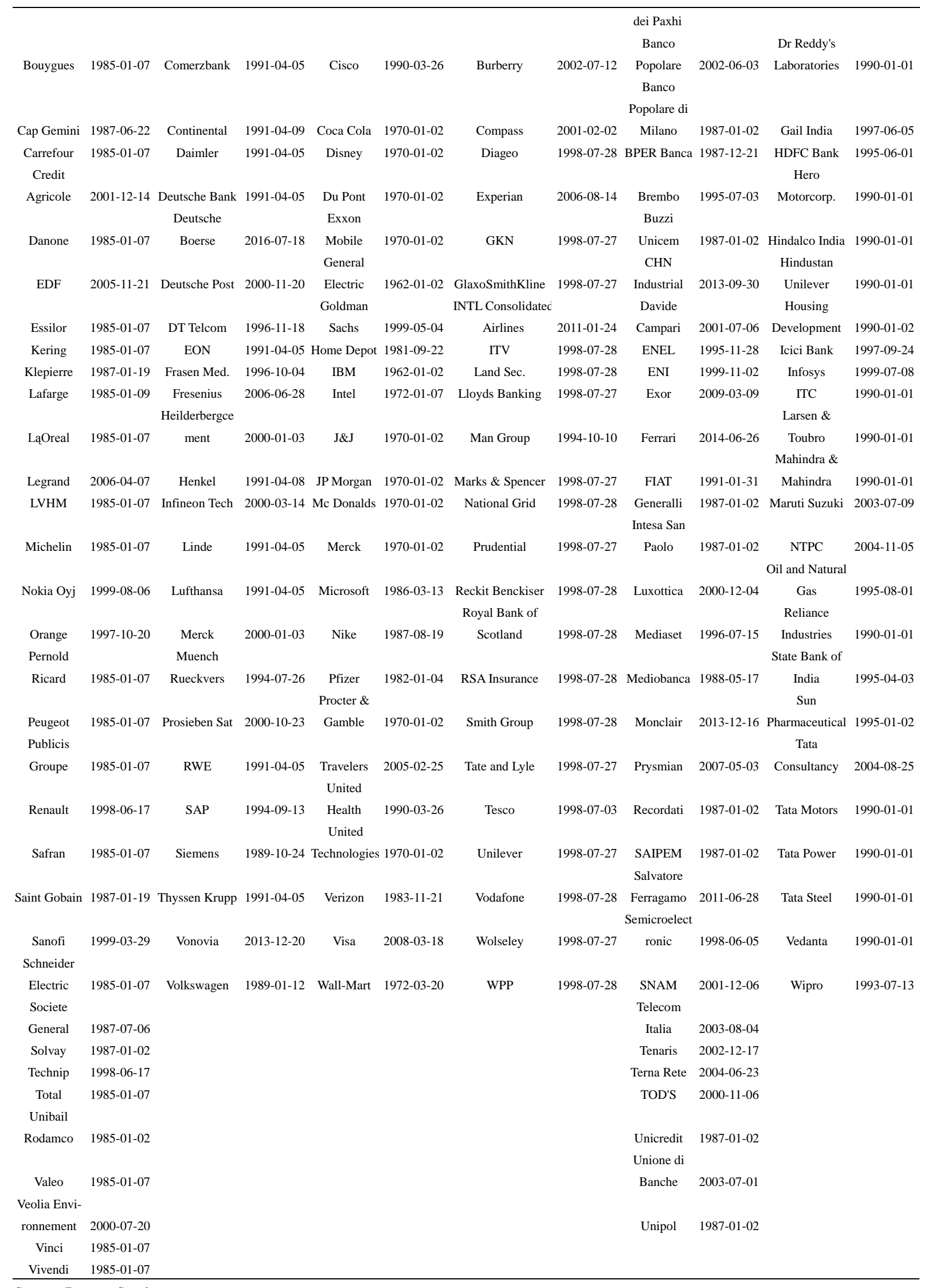

Source: Reuters Service. 
Table A2. Components of the Nikkei 225 index included in the analysis and their first date of quotation

\begin{tabular}{|c|c|c|c|c|c|c|c|c|c|c|c|}
\hline Company & Date & Company & Date & Company & Date & Company & Date & Company & Date & Company & Date \\
\hline Advantest & 1984-01-04 & Fuji Electric & 1984-01-04 & Kuraray & 1984-01-04 & Nippon Soda & 1984-01-04 & Shizuoka Bank & 1984-01-04 & Tokyo Gas & 1984-01-04 \\
\hline AEON & 1984-01-04 & Fuji Film & 1984-01-04 & Kyocera & 1984-01-04 & Nippon Suisan & 1984-01-04 & Showa Denko & 1984-01-04 & Tokyo Marine & 2002-04-01 \\
\hline Ajinomoto & 1984-01-04 & Fuji Heavy Ind & 1984-01-04 & Kyowa & 1984-01-04 & Nippon Yusen & 1984-01-04 & Showa Shell & 1984-01-04 & Tokyo Ord & 1984-05-08 \\
\hline Alps Electr & 1984-01-04 & Fujikura & 1984-01-04 & Marubem & 1984-01-04 & $\begin{array}{l}\text { Nissan } \\
\text { Nissen }\end{array}$ & 1984-01-04 & Sky Perfect & 2007-04-02 & Tokyo Tatemono & 1984-01-04 \\
\hline Amada & 1984-01-04 & Fujitsu & 1984-01-04 & Maruha Nichiro & 2014-04-01 & Chemical & 1984-01-04 & SMFG & $2002-12-02$ & Toppan Printing & 1984-01-04 \\
\hline Ana Holdings & 1984-01-04 & Fukuoka Fin & 2007-04-02 & Marui Group & 1984-01-04 & Nisshin Steel & 2012-10-01 & Softbank & 1994-07-22 & Toray Inds & 1984-01-04 \\
\hline Aozora Bank & 2006-11-14 & Furukawa Elec & 1984-01-04 & Matsui Sec. & 2001-08-01 & Nisshinbo & 1984-01-04 & Soijtz & 2003-04-01 & Toshiba & 1984-01-04 \\
\hline Asahi Glass & 1984-01-04 & GS Yuasa & 2004-04-01 & Mazda & 1984-01-04 & Nitto Denko & 1984-01-04 & Sompo Holdings & $2010-04-01$ & Tosoh & 1984-01-04 \\
\hline Asahi Kasei & 1984-01-04 & Heiwa R & 1984-01-04 & Meidensha & 1984-01-04 & $\begin{array}{l}\text { Nittobo } \\
\text { Nomura }\end{array}$ & 1984-01-04 & Sony & 1984-01-04 & Toto & 1984-01-04 \\
\hline $\begin{array}{l}\text { Ashi Group } \\
\text { Astellas }\end{array}$ & 1984-01-04 & Hino & 1984-01-04 & Meiji Holdings & 2009-04-01 & Holdings & 1984-01-04 & Sony Dinancial & $2007-10-11$ & Toyo Seikan & 1984-01-04 \\
\hline Pharmas & 1984-01-04 & Hitachi & 1984-01-04 & Minebe Mitsumi & 1984-01-04 & NPSTL & 1984-01-04 & Sumco & $2005-11-17$ & Toyobo & 1984-01-04 \\
\hline Bridgestone & 1984-01-04 & Hitachi Const & 1984-01-04 & Mitsub Chem & $2005-10-03$ & NSK & 1984-01-04 & Sumitomo & 1984-01-04 & Toyota & 1984-01-04 \\
\hline Canon & 1984-01-04 & Hitachi Zosen & 1984-01-04 & Mitsub Logistic & 1984-01-04 & NTN & $1984-01-04$ & Sumitomo Chem & 1984-01-04 & Toyota Tsusho & 1984-01-04 \\
\hline Casio Computer & 1984-01-04 & Hokuetsu Kishu & $1984-01-04$ & Mitsub UFJ & 2001-04-02 & NTT & $1987-02-10$ & $\begin{array}{c}\text { Sumitomo Elec } \\
\text { Sumitomo }\end{array}$ & 1984-01-04 & Trend Micro & 1998-08-18 \\
\hline Central Japan & 1997-10-08 & Honda & 1984-01-04 & Mitsubishi & 1984-01-04 & NTT Data & $1995-04-26$ & Heavy & 1984-01-04 & Ube Ind. & 1984-01-04 \\
\hline Chiba Bank & 1984-01-05 & IHI & 1984-01-04 & Mitsubishi Elec & 1984-01-04 & NTT Docomo & $1998-10-22$ & $\begin{array}{c}\text { Sumitomo M\&M } \\
\text { Sumitomo }\end{array}$ & 1984-01-04 & Unitika & 1984-01-04 \\
\hline Chiyoda & 1984-01-04 & Inpex & 2006-04-03 & Mitsubishi Est & 1984-01-04 & Obayashi & 1984-01-04 & Mitsui & 2002-01-31 & West Japan & 1996-10-08 \\
\hline Chubu Ele & 1984-01-04 & Isuzu & 1984-01-04 & Mitsubishi Heavy & 1984-01-04 & Odakyu Elec & 1984-01-04 & $\begin{array}{l}\text { Sumitomo Osaka } \\
\text { Sumitomo }\end{array}$ & $1984-01-04$ & Yahoo Japan & 1997-11-04 \\
\hline Chugai Pharm & 1984-01-04 & $\begin{array}{l}\text { Itochu } \\
\text { J. Front }\end{array}$ & 1984-01-04 & Mitsubishi Matls & 1984-01-04 & OJI Holdings & 1984-01-04 & Realty & 1984-01-04 & $\begin{array}{l}\text { Yamaha } \\
\text { Yamato }\end{array}$ & 1984-01-04 \\
\hline Citizen Watch & 1984-01-04 & Retailing & 2007-09-03 & Mitsubishi Motor & 1988-12-05 & Oki Elec & 1984-01-04 & Suzuki & 1984-01-05 & Holdings & 1984-01-04 \\
\hline Cobe Steel & 1984-01-04 & Japan Steel & 1984-01-04 & Mitsui & 1984-01-04 & Okuma & 1984-01-04 & T\&D Holdings & 2004-04-01 & Yaskawa & 1984-01-04 \\
\hline Comsys & 2003-09-29 & Japan Tabacco & $1994-10-27$ & Mitsui Eng & 1984-01-04 & Olympus & 1984-01-04 & Taiheyo Cement & 1984-01-04 & $\begin{array}{l}\text { Yokogawa } \\
\text { Yokohama }\end{array}$ & 1984-01-04 \\
\hline Credit Saison & 1984-01-04 & JFE Holdings & $2002-09-26$ & $\begin{array}{l}\text { Mitsui Fudosan } \\
\text { Mitsui }\end{array}$ & 1984-01-04 & Osaka Gas & 1984-01-04 & Taisei & 1984-01-04 & Rubber & 1984-01-04 \\
\hline Da Nip & 1984-01-04 & JGC & 1984-01-04 & Min\&Smelt & 1984-01-04 & Pacific metals & 1984-01-04 & Taiyo Yuden & 1984-01-04 & & \\
\hline Dai Ichi Life & 2010-04-01 & JTEKT & 1984-01-04 & Mitsui Ord & 1984-01-04 & Panasonic & 1984-01-04 & Takara & 1984-01-04 & & \\
\hline Daichi Sankuyo & $2005-09-28$ & JX Holdings & 2010-04-01 & Mitsui Osk Lines & 1984-01-04 & $\begin{array}{l}\text { Pioneer } \\
\text { Resona }\end{array}$ & 1984-01-04 & Takashimaya & 1984-01-04 & & \\
\hline Daikin Ind & 1984-01-04 & Kaima & 1984-01-04 & Mitsumi Electr & 1984-01-04 & Holdings & $2001-12-11$ & Takeda & 1984-01-04 & & \\
\hline Dainpn Sumi & 1984-01-04 & Kansai Elec & 1984-01-04 & Mizuho Financial & 2003-03-12 & $\begin{array}{c}\text { Ricoh } \\
\text { Sapporo }\end{array}$ & 1984-01-04 & TDK & 1984-01-04 & & \\
\hline $\begin{array}{c}\text { Daiwa House } \\
\text { Daiwa }\end{array}$ & 1984-01-04 & $\begin{array}{c}\text { Kao } \\
\text { Kawasaki }\end{array}$ & 1984-01-04 & $\begin{array}{l}\text { Mnisshin } \\
\text { MS\&AD }\end{array}$ & 1984-01-04 & $\begin{array}{l}\text { Holdings } \\
\text { Screen }\end{array}$ & 1984-01-04 & Teijin & 1984-01-04 & & \\
\hline Securities & 1984-01-04 & $\begin{array}{c}\text { Heavy } \\
\text { Kawasaki }\end{array}$ & 1984-01-04 & Insurance & 2008-04-01 & Holdings & 1984-01-04 & Terumo & 1984-01-04 & & \\
\hline Denka & 1984-01-04 & Kisen & 1984-01-04 & NEC & 1984-01-04 & Secom & 1984-01-04 & TGK Insulators & 1984-01-04 & & \\
\hline Denso & 1984-01-04 & KDDI & 1993-09-03 & NH Foods & 1984-01-04 & Sekisui & 1984-01-04 & Tobu RW & 1984-05-08 & & \\
\hline Dentsu & 2001-11-30 & Keio Ord & 1984-01-04 & Nichirei & 1984-01-04 & Setan Mitsuko & $2008-04-01$ & Toho SVC & 1984-01-04 & & \\
\hline Dowa Holdings & 1984-01-04 & Keisei Electic & 1984-01-04 & $\begin{array}{c}\text { Nikkon } \\
\text { Nippon Elec }\end{array}$ & 1984-01-04 & Seven \& I & 2005-09-01 & Toho Zinc & 1984-01-04 & & \\
\hline Durukawa & 1984-01-04 & Kikkoman & 1984-01-04 & Glass & 1984-01-04 & Sharp & 1984-01-04 & Tokai Carbon & 1984-01-04 & & \\
\hline East Japan & $1993-10-26$ & Kirin & 1984-01-04 & Nippon Express & 1984-01-04 & Shimizu & 1984-01-04 & Tokuyama & 1984-01-04 & & \\
\hline Ebara & 1984-01-04 & Komatsu & 1984-01-04 & $\begin{array}{l}\text { Nippon Kayaku } \\
\text { Nippon Light }\end{array}$ & 1984-01-04 & Shin Etsu & 1984-01-04 & Tokyo Dome & 1984-01-04 & & \\
\hline Eisai & 1984-01-04 & Konami & 1988-02-19 & Metal & 2012-10-01 & Shinsei Bank & 2004-02-19 & Tokyo Ele PWR & 1984-01-04 & & \\
\hline Fanuc & 1984-01-04 & Konica Minolta & 1984-01-04 & $\begin{array}{l}\text { Nippon Paper } \\
\text { Nippon Sheet }\end{array}$ & 2013-04-01 & Shinseido & 1984-01-04 & Tokyo Electron & 1984-01-04 & & \\
\hline Fast Retailing & 1997-04-02 & Kubota & 1984-01-04 & GLS & 1984-01-04 & Shiongoi & 1984-01-04 & Tokyo Fudosan & 2013-10-01 & & \\
\hline
\end{tabular}

Source: Reuters Service. 
Table A3. Example of p values calculation for returns of CAC40 components with the use of the Z statistics. Shaded cells represent cases when $\mathrm{p}$ value was lower than 0.05

\begin{tabular}{|c|c|c|c|c|c|c|c|c|c|c|c|c|c|c|c|c|c|c|c|}
\hline \multirow[b]{2}{*}{ Comapny Name } & \multirow[b]{2}{*}{ First date } & \multicolumn{4}{|c|}{ 13th } & \multicolumn{4}{|c|}{ 13th and Friday } & \multicolumn{4}{|c|}{ 13th and Tuesday } & \multicolumn{3}{|c|}{ 4th } & & \multicolumn{2}{|c|}{ 13th Friday 13th Tuesday } \\
\hline & & $\mathrm{C}-\mathrm{C}$ & OV & $\mathrm{O}-\mathrm{O}$ & $\mathrm{O}-\mathrm{C}$ & $\mathrm{C}-\mathrm{C}$ & OV & $\mathrm{O}-\mathrm{O}$ & $\mathrm{O}-\mathrm{C}$ & $\mathrm{C}-\mathrm{C}$ & OV & $\mathrm{O}-\mathrm{O}$ & $\mathrm{O}-\mathrm{C}$ & $\mathrm{C}-\mathrm{C}$ & OV & $\mathrm{O}-\mathrm{O}$ & $\mathrm{O}-\mathrm{C}$ & $\mathrm{C}-\mathrm{C}$ & $\mathrm{C}-\mathrm{C}$ \\
\hline Accor & 1985-01-07 & 0.8176 & 0.2341 & 0.8137 & 0.4960 & 0.8973 & 0.5667 & 0.9144 & 0.7153 & 0.8939 & 0.9846 & 0.2881 & 0.8319 & 0.3077 & 0.4744 & 0.6617 & 0.2888 & 0.5900 & 0.7311 \\
\hline Air Liquide & 1985-01-07 & 0.0474 & 0.3534 & 0.9459 & 0.0798 & 0.2765 & 0.8876 & 0.7006 & 0.1462 & 0.6116 & 0.6402 & 0.7891 & 0.8551 & 0.3493 & 0.3887 & 0.4256 & 0.7457 & 0.1165 & 0.9917 \\
\hline Airbus & 1999-06-04 & 0.5301 & 0.9075 & 0.5062 & 0.5030 & 0.7954 & 0.1990 & 0.0068 & 0.5767 & 0.3244 & 0.4169 & 0.4569 & 0.7649 & 0.9741 & 0.4221 & 0.4915 & 0.6183 & 0.6491 & 0.6899 \\
\hline Arcelormittal & 1997-08-08 & 0.6598 & 0.9957 & 0.0127 & 0.6507 & 0.2040 & 0.4597 & 0.8433 & 0.4058 & 0.3431 & 0.8194 & 0.3436 & 0.1573 & 0.3526 & 0.3851 & 0.9884 & 0.7210 & 0.4814 & 0.1528 \\
\hline AXA & 1985-01-07 & 0.8853 & 0.3666 & 0.5850 & 0.5885 & 0.3518 & 0.9332 & 0.4302 & 0.3407 & 0.9269 & 0.7582 & 0.4397 & 0.6013 & 0.2881 & 0.4848 & 0.6346 & 0.2900 & 0.3728 & 0.4552 \\
\hline BNP Paribas & 1993-10-18 & 0.4281 & 0.2760 & 0.5248 & 0.8569 & 0.5317 & 0.1435 & 0.2913 & 0.8493 & 0.0814 & 0.1026 & 0.3557 & 0.4913 & 0.3703 & 0.4241 & 0.3250 & 0.7317 & 0.9436 & 0.2972 \\
\hline Bouygues & 1985-01-07 & 0.5437 & 0.5297 & 0.9214 & 0.8069 & 0.3403 & 0.0640 & 0.2860 & 0.8945 & 0.2840 & 0.5040 & 0.9226 & 0.2604 & 0.1558 & 0.1691 & 0.1748 & 0.7193 & 0.9069 & 0.1789 \\
\hline Cap Gemini & $1987-06-22$ & 0.5629 & 0.9424 & 0.7303 & 0.4691 & 0.6643 & 0.6611 & 0.7029 & 0.8257 & 0.4848 & 0.8482 & 0.5977 & 0.1287 & 0.0879 & 0.2412 & 0.3008 & 0.1552 & 0.6962 & 0.0876 \\
\hline Carrefour & 1985-01-07 & 0.5294 & 0.7641 & 0.7750 & 0.6171 & 0.6341 & 0.8283 & 0.9174 & 0.6787 & 0.4939 & 0.9244 & 0.4048 & 0.3555 & 0.0823 & 0.2533 & 0.1798 & 0.0273 & 0.8609 & 0.2702 \\
\hline Credit Agricole & 2001-12-14 & 0.7674 & 0.3151 & 0.2261 & 0.7636 & 0.2054 & 0.4955 & 0.5644 & 0.2662 & 0.1227 & 0.1488 & 0.1401 & 0.9096 & 0.3763 & 0.9323 & 0.9270 & 0.3049 & 0.2260 & 0.5464 \\
\hline Danone & 1985-01-07 & 0.6532 & 0.5116 & 0.7441 & 0.2948 & 0.1867 & 0.8783 & 0.6140 & 0.1387 & 0.8595 & 0.2031 & 0.2730 & 0.0311 & 0.2486 & 0.4341 & 0.4579 & 0.0701 & 0.0886 & 0.0661 \\
\hline EDF & 2005-11-21 & 0.0576 & 0.3856 & 0.6871 & 0.0437 & 0.0417 & 0.5258 & 0.9705 & 0.0167 & 0.1663 & 0.3948 & 0.7684 & 0.0845 & 0.2498 & 0.2930 & 0.6202 & 0.0622 & 0.0048 & 0.1172 \\
\hline Essilor & 1985-01-07 & 0.5124 & 0.2766 & 0.3408 & 0.8195 & 0.7067 & 0.8502 & 0.8212 & 7220 & 0.7517 & 0.7904 & 0.2795 & 0.8749 & 0.2480 & 0.2165 & 0.1570 & 0.7775 & .5438 & 0.8467 \\
\hline Kering & 1985-01-07 & 0.8184 & 0.5684 & 0.3548 & 0.8689 & 0.4721 & 0.1266 & 0.0700 & 0.9570 & 0.7239 & 0.6688 & 0.4980 & 0.9794 & 0.1810 & 0.2117 & 0.2473 & 0.6380 & 0.9819 & 0.7238 \\
\hline Klepierre & 1987-01-19 & 0.2225 & 0.9598 & 0.6338 & 0.1689 & 0.0633 & 0.3510 & 0.4134 & 0.1309 & 0.3424 & 0.0811 & 0.1667 & 0.9278 & 0.2459 & 0.3680 & 0.4873 & 0.2530 & 0.1569 & 0.9936 \\
\hline Lafarge & 1985-01-09 & 0.3751 & 0.4163 & 0.5914 & 0.0848 & 0.2352 & 0.8694 & 0.2133 & 0.1338 & 0.9215 & 0.2993 & 0.7420 & 0.5325 & 0.1794 & 0.2434 & 0.1909 & 0.5768 & 0.1778 & 6100 \\
\hline LąOreal & 1985-01-07 & 0.2768 & 0.4645 & 0.9482 & 0.4535 & 0.9333 & 0.6815 & 0.3449 & 0.7011 & 0.5637 & 0.8062 & 0.5638 & 0.5412 & 0.3078 & 0.4876 & 0.2845 & 0.3553 & 0.4878 & 0.6356 \\
\hline Legrand & 2006-04-07 & 0.7616 & 0.0646 & 0.8871 & 0.1859 & 0.1855 & 0.7114 & 0.6145 & 0.1079 & 0.1320 & 0.3211 & 0.5859 & 0.1695 & 0.8774 & 0.4938 & 0.4447 & 0.6316 & .1255 & 1489 \\
\hline LVHM & 1985-01-07 & 0.9180 & 0.6574 & 0.4420 & 0.6393 & 0.1080 & 0.2267 & 0.3905 & 0.2595 & 0.2914 & 0.3420 & 0.0986 & 0.4996 & 0.2747 & 0.3619 & 0.3141 & 0.4646 & 0.3312 & 0.4508 \\
\hline Michelin & 1985-01-07 & 0.0927 & 0.5681 & 0.2960 & 0.1173 & 0.5619 & 0.9835 & 0.5489 & 0.5247 & 0.1855 & 0.7997 & 0.6850 & 0.0488 & 0.2785 & 0.4214 & 0.5557 & 0.4281 & .3877 & .0227 \\
\hline Nokia Oyj & 1999-08-06 & 0.1517 & 0.8100 & 0.0640 & 0.0513 & 0.1602 & 0.2898 & 0.1501 & 0.5697 & 0.1054 & 0.4704 & 0.8393 & 0.3338 & 0.4666 & 0.5046 & 0.8286 & 0.7031 & 0.5422 & 0.2474 \\
\hline Orange & $1997-10-20$ & 0.1572 & 0.6050 & 0.9573 & 0.2085 & 0.7060 & 0.5699 & 0.9159 & 0.4605 & 0.0337 & 0.4100 & 0.4806 & 0.0300 & 0.4548 & 0.4751 & 0.2737 & 0.9660 & 0.5778 & .0336 \\
\hline Pernold Ricard & 1985-01-07 & 0.1341 & 0.5053 & 8741 & 0.2029 & 0. & 0.1191 & 0.6081 & 2466 & 0.6497 & 0.6718 & 0.2895 & 0.7982 & 0.3146 & 0.3554 & 0.5147 & 0.8138 & 0.2264 & .5398 \\
\hline Peugeot & 1985-01-07 & 0.3661 & 0.5666 & 0.2347 & 0.4870 & 0.7181 & 0.2952 & 0.5091 & 0.9127 & 0.0799 & 0.4779 & 0.2690 & 0.0287 & 0.1175 & 0.2866 & 0.4136 & 0.1161 & 0.8724 & 0.0095 \\
\hline Public & 1985-01-07 & 0.5373 & 0.8591 & 5863 & 116 & 0.0846 & 0.4056 & 4488 & 50 & 28 & 0.8398 & 0.7099 & 268 & 9 & 2852 & 4049 & 7383 & .0924 & 7816 \\
\hline Renault & 1998-06-17 & 0.4835 & 0.3948 & 0.1793 & 0.7811 & 0.8529 & 0.8671 & 0.8532 & 0.7609 & 0.0089 & 0.1864 & 0.3243 & 0.0010 & 0.4050 & 0.3494 & 0.3137 & 0.8256 & 0.7359 & .0004 \\
\hline Safran & 1985-01-07 & 0.5401 & 0.5189 & 0.0588 & 0.2448 & 0.4941 & 0.8743 & 0.7539 & 0.5947 & 0.7708 & 0.8717 & 0.1938 & 0.8477 & 0.3275 & 0.2217 & 0.2322 & 0.5080 & 0.5474 & 0.6079 \\
\hline Saint Gobain & 1987-01-19 & 0.6982 & 0.3535 & 0.3138 & 0.8359 & 0.4810 & 0.5383 & 0.2617 & 0.6729 & 0.3508 & 0.9392 & 0.9052 & 0.0845 & 0.6246 & 0.4232 & 0.6073 & 0.4210 & 0.6694 & 0.0682 \\
\hline Sanofi & 1999-03-29 & 0.0064 & 0.1752 & 0.8524 & 0.0335 & 0.9616 & 0.4796 & 0.3969 & 0.6883 & .0412 & 0.1536 & 0.9469 & 0.0721 & 0.4221 & 0.3014 & 0.3615 & 0.1509 & 0.5909 & 0915 \\
\hline Schneider Electric & 1985-01-07 & 0.9122 & 0.4759 & 0.2959 & 0.6722 & 0.8768 & 0.0741 & 0.2774 & 0.3095 & 0.2972 & 0.4930 & 0.7409 & 0.0696 & 0.6595 & 0.3414 & 0.5633 & 0.1388 & 0.3754 & .0293 \\
\hline Societe General & 1987-07-06 & 0.6042 & 0.7231 & 0.2825 & 0.7403 & 0.8893 & 0.8267 & 0.7369 & 0.7511 & 0.7601 & 0.4995 & 0.7125 & 0.7829 & 0.2944 & 0.6740 & 0.6417 & 0.1007 & 0.6577 & 0.9133 \\
\hline Solvay & 1987-01-02 & 0.4906 & 0.7941 & 0.9860 & 0.5240 & 0.5792 & 0.1844 & 0.4912 & 0.9733 & .0603 & 0.1266 & 0.6569 & 0.1359 & 0.1474 & 0.3258 & 0.4075 & 0.0551 & 0.8236 & 0.1030 \\
\hline Technip & 1998-06-17 & 0.6201 & 0.1179 & 0.4561 & 0.5731 & 0.7706 & 0.1288 & 0.6984 & 0.2887 & 0.0485 & 0.1262 & 0.6300 & 0.4181 & 0.3534 & 0.3661 & 0.2179 & 0.8110 & 0.2731 & 0.2991 \\
\hline Total & 1985-01-07 & 0.3091 & 0.2559 & 0.4527 & 0.7303 & 0.7353 & 0.8317 & 0.2628 & 0.8137 & 0.6699 & 0.6292 & 0.5167 & 0.2883 & 0.4235 & 0.3911 & 0.3350 & 0.9421 & 0.7529 & 0.2921 \\
\hline Unibail Rodamco & 1985-01-02 & 0.4204 & 0.3329 & 0.3589 & 0.8267 & 0.4014 & 0.2367 & 0.8401 & 0.8670 & 0.8268 & 0.8113 & 0.6780 & 0.6132 & 0.2794 & 0.3555 & 0.3015 & 0.5205 & 0.8762 & 0.4317 \\
\hline Valeo & 1985-01-07 & 0.8652 & 0.6443 & 0.8895 & 0.8119 & 0.5539 & 0.9822 & 0.4983 & 0.2427 & 0.7484 & 0.9890 & 0.8633 & 0.6380 & 0.3412 & 0.3859 & 0.3859 & 0.6303 & 0.2574 & 0.5073 \\
\hline Veolia & & & & & & & & & & & & & & & & & & & \\
\hline Environnement & 2000-07-20 & 0.9324 & 0.5820 & 0.4416 & 0.6961 & 0.0642 & 0.7654 & 0.9707 & 0.1346 & 0.1888 & 0.2454 & 0.5700 & 0.2105 & 0.0101 & 0.6788 & 0.5297 & 0.0107 & 0.1029 & 0.1294 \\
\hline Vinci & 1985-01-07 & 0.7380 & 0.9322 & 0.2796 & 0.5950 & 0.1510 & 0.1707 & 0.6252 & 0.4952 & 0.1366 & 0.2455 & 0.6959 & 0.1918 & 0.2 & 0.2246 & 0.3762 & 0.9039 & 0.5576 & .0802 \\
\hline Vivendi & 1985-01-07 & 0.8561 & 0.5557 & 0.1891 & 0.5391 & 0.3936 & 0.8058 & 0.3391 & 0.2994 & 0.7375 & 0.6457 & 0.7870 & 0.8659 & 0.2207 & 0.3297 & 0.3399 & 0.4280 & 0.3662 & 0.9803 \\
\hline
\end{tabular}

Source: Reuters Service.

\section{Copyrights}

Copyright for this article is retained by the author(s), with first publication rights granted to the journal.

This is an open-access article distributed under the terms and conditions of the Creative Commons Attribution license (http://creativecommons.org/licenses/by/4.0/). 